\title{
LAICE CubeSat Mission for Gravity Wave Studies
}

John Westerhoff ${ }^{\mathrm{a}}$, Gregory Earle ${ }^{\mathrm{b}}$, Rebecca Bishop ${ }^{\mathrm{c}}$, Gary R. Swenson ${ }^{\mathrm{a}}$, Sharon Vadas ${ }^{\mathrm{d}}$, James Clemmons $^{\mathrm{c}}$, Ryan Davidson ${ }^{\mathrm{b}}$, Lucy Fanelli ${ }^{\mathrm{b}}$, Chad Fish ${ }^{\mathrm{b}}$, Vidur Garg ${ }^{\mathrm{b}}$, Alex Ghosh ${ }^{\mathrm{a}}$, Bindu B. Jagannatha $^{\mathrm{a}}$, Erik Kroeker ${ }^{\mathrm{a}}$, Peter Marquis ${ }^{\mathrm{b}}$, Daniel Martin ${ }^{\mathrm{b}}$, Stephen Noel ${ }^{\mathrm{b}}$, Cameron Orr ${ }^{\mathrm{b}}$, Robert Robertson ${ }^{b}$

${ }^{a}$ Remote Sensing and Space Science Laboratory

University of Illinois at Urbana-Champaign

315A Coordinated Science Lab, MC-228

1308 W. Main St.

Urbana, IL 61801

${ }^{b}$ Space@VT

Virginia Tech

1901 Innovation Drive, Suite 1000

Blacksburg, VA 24060

${ }^{c}$ Aerospace Corporation

2310 E. El Segundo Blvd.

El Segundo, CA 90245

${ }^{d}$ NorthWest Research Associates

4118 148th Ave NE

Redmond, WA 98052

\section{Corresponding author:}

John Westerhoff

Email: westerho@illinois.edu

Ph: (773) 720-7880 


\begin{abstract}
The Lower Atmosphere/Ionosphere Coupling Experiment (LAICE) CubeSat mission will focus on understanding the interaction of atmospheric gravity waves generated by weather systems in the lower atmosphere with the mesosphere, lower thermosphere, and ionosphere (MLTI). Specifically, LAICE will focus on the energy and momentum delivered by these waves and attempt to connect the wave sources and the wave effects in three widely different altitude ranges, substantially adding to our knowledge of critical coupling processes between disparate atmospheric regions. The LAICE mission consists of a $6 \mathrm{U}$ CubeSat with a four-instrument payload. The retarding potential analyzer (RPA) will provide in-situ ion density and temperature measurements. A four-channel photometer will measure density and temperature variations in the mesosphere through observations of $\mathrm{O}_{2}(0,0)$ Atmospheric band and $\mathrm{O}_{2}$ Herzberg I band airglows. There are two pressure sensors that comprise the Space Pressure Suite (SPS): the Space Neutral Pressure Instrument (SNeuPI) and the LAICE Ionization gauge Neutral Atmosphere Sensor (LINAS). Both will provide neutral density measurements, but SNeuPI is a prototype sensor that will be validated by LINAS. This CubeSat mission, scheduled for launch in early 2016 from the International Space Station, provides a cost-effective approach to measuring low altitude in-situ parameters along with simultaneous imaging that is capable of addressing the fundamental questions of atmospheric gravity wave coupling in the MLTI region.
\end{abstract}

\title{
Keywords:
}

cubesat; atmospheric coupling; gravity waves; airglow; ionosphere

\section{Introduction}

The Lower Atmosphere/Ionosphere Coupling Experiment (LAICE) is a groundbreaking mission in low Earth orbit (LEO) focused on understanding how atmospheric gravity waves generated by weather systems in the lower atmosphere propagate and deliver energy and momentum into the mesosphere, lower thermosphere, and ionosphere (MLTI). These waves are an important facet of atmospheric physics, but their effects in the thermosphere and ionosphere are under-explored. They strongly influence the dynamics of the media through which they travel via momentum and energy deposition at altitudes well above their source regions, and they can seed the development of plasma instabilities that scintillate and disrupt radio propagation.

LAICE will focus on these waves and attempt to connect their causes and effects in three widely different altitude ranges, substantially adding to our knowledge of a critical coupling process between disparate atmospheric regions.

LAICE will utilize in-situ instrumentation to measure the perturbations the waves produce in both neutral and ion densities at F-region heights, while on-board photometers simultaneously remotely measure the wavelengths and amplitudes of the wave fields in the upper mesosphere. Subsequent modeling coupled with meteorological data will be used to study the connections between tropospheric storms and the MLTI system using ray tracing techniques that include the effects of viscosity and wave dissipation. This mission data will also be applied to additional coupling studies, e.g. analyzing connections between other wave-generating mechanisms and the MLTI system.

\subsection{Background and motivation}


In Earth's high latitude regions the ionosphere is primarily influenced by energy flowing downward along magnetic field lines from high altitudes, but at middle and low latitudes the ionosphere is also affected by energy and momentum transferred via upward-propagating gravity waves. Bauer (1958) was one of the first to notice such an effect, using ionogram data to reveal variations in the height of the F-region associated with a tropical hurricane. Subsequent studies with greater sensitivity confirmed these early observations (e.g., Bishop et al., 2006), while other studies have reported ionospheric manifestations of less severe terrestrial weather systems, including tropical storms, tornadoes, and even thunderstorms (Pierce and Coroniti, 1966; Hung et al., 1978; Larsen et al., 1982; McClure, 1998; Earle et al., 2008, 2010). Importantly, every one of these studies cites gravity waves (e.g. Hines, 1960) as the most likely mechanism by which energy is transferred from low to high altitudes.

The wealth of observational evidence for tropospheric weather-induced gravity wave influences on the ionosphere is not disputed, but despite the half century over which these phenomena have been observed the relative magnitude of the energy transferred, the spatial scales of the affected regions, the locations of the strongest coupling regions, and the climatology of the coupling events are not well known. The references above provide anecdotal observations of ionospheric effects that appear to be driven by weather systems, but we do not have detailed measurements relevant to the coupling processes, largely because the region where it occurs is too low to be readily accessible to satellites, and not easily monitored by ground-based systems.

Theory predicts that gravity waves (GWs) with large vertical and horizontal group velocities can propagate to high altitudes and survive the pervasive molecular viscosity that is characteristic of the thermosphere (i.e., z>110 km) (Vadas and Fritts, 2005, 2006; Vadas and Liu, 2009, 2013; Liu and Vadas, 2013; Vadas et al., 2014). Questions about the influences of these waves are among the most important unknowns in atmospheric coupling studies. For example, are the electric fields generated in highly conductive regions by $\mathrm{GW}$-driven perturbations important drivers of higher altitude plasma drifts, as some studies suggest (Hanson and Johnson, 1992; Farrell et al., 1994)? Do wave disturbances from below occur preferentially in particular geographic regions, at particular local times, or in specific seasons? How are active wave regions in the thermosphere related to the wave spectrum in the underlying mesosphere and to terrestrial weather systems in the troposphere? Is there a storm severity threshold or governing temporal characteristic controlling the efficacy of upward wave coupling? These are just a few of the fundamental questions whose answers have eluded atmospheric scientists largely because of restricted access to the altitudes of interest. In-situ wave observations are needed to address issues of such a global nature, but these must occur at relatively low altitudes where the short lifetimes of traditional satellite missions are unacceptable relative to their high cost.

\subsection{LAICE Mission}

The CubeSat approach to space science in LEO helps to mitigate restrictions to such research, and enables missions that can address these and other fundamental science questions at a reasonable cost. The LAICE CubeSat mission has been designed address these questions with two fundamental mission goals:

1. Systematically observe and correlate gravity waves that have large vertical wavelengths (>30 km) by combining remote sensing of wave-induced airglow perturbations in the upper mesosphere with in-situ measurements of ion and neutral density fluctuations at ionospheric F-region altitudes; 
2. Produce global maps of active gravity wave coupling regions in the mid- and low-latitude ionosphere over multiple seasons at all local times, so that global patterns and climatological variations can be quantitatively compared to and correlated with terrestrial weather systems.

Though the focus of LAICE is on waves generated in the troposphere which propagate upward to ionospheric heights, GWs have other sources, e.g. Joule heating of neutrals during magnetic activity and GWs excited by the solar terminator. These other sources have been studied for decades, however (Hocke and Schlegel, 1996). Gravity waves propagating to the thermosphere from lower atmospheric sources have only been known to occur for the last decade, and have gained increasing importance in the community for causing large fluctuations in the thermosphere and ionosphere when the $\mathrm{Kp}$ is low. Deep convection is likely an important everyday source of gravity waves in the thermosphere based on recent modeling studies (Vadas and Liu, 2009, 2013; Liu and Vadas, 2013; Vadas et al, 2014).

A tantalizing glimpse of the potential of the LAICE mission is provided in Figure 1, which shows data obtained in the last 3 weeks of life of the Dynamics Explorer 2 (DE-2) satellite, when its orbit had decayed below $300 \mathrm{~km}$. The plasma data shown in the figure are from the retarding potential analyzer (RPA) and ion drift meter (IDM) aboard DE-2, and the neutral data are from the wind and temperature spectrometer (WATS). Detailed descriptions of the design and functionality of these instruments have been previously published (Hanson et al., 1973; Heelis et al., 1981; Spencer et al., 1981).

The figure shows an example in which the plasma density (top panel) in the bottom-side Fregion undergoes $\pm 30-100 \%$ fluctuations over horizontal scales of a few hundred kilometers. These fluctuations are strikingly anti-correlated with the vertical motions of the plasma and the neutral gas (bottom two panels). The relative variations in the neutral density ( $2^{\text {nd }}$ panel) are much smaller $(<20 \%)$ than the plasma variations because of the denser neutral background. Thus the small amplitude variation in the neutral gas due to the gravity wave produces a much larger variation in the ionized medium. The anti-correlation occurs because DE- 2 was below the F-peak during these final weeks of operation, so the neutral density gradient at the satellite altitude was downward, while the plasma density gradient was upward. Consequently when gravity waves in the neutral atmosphere lifted the atmosphere and ionosphere, the neutral density increased while the plasma density decreased (top two panels in the figure). In regions where the atmosphere and ionosphere were displaced downward the effect was just the opposite.

Comparisons with model spectra show convincingly that these oscillations are gravity waves that propagate in the thermosphere below $300 \mathrm{~km}$ altitude (Earle et al., 2008).

DE-2 and CHAMP both measured wave fluctuations when the Kp was low. Gravity wave amplitudes grow exponentially with altitude. Therefore, by the time these gravity waves get to the thermosphere, their amplitudes are large, driving large accelerations in the thermosphere at $\sim 200 \mathrm{~km}$ where they dissipate $\left(0.1-1 \mathrm{~m} / \mathrm{s}^{2}\right)$, creating large horizontal neutral winds $(\sim 50-200$ $\mathrm{m} / \mathrm{s}$ ), and exciting medium to large-scale secondary gravity waves that can propagate to 400-500 $\mathrm{km}$ altitude (Vadas and Liu, 2009, 2013; Liu and Vadas, 2013; Vadas et al, 2014). These secondary gravity waves have likely already been observed (e.g., Vadas and Crowley, 2010), and were likely the waves seen by DE- 2 and CHAMP at low Kp. 
Unfortunately the few DE-2 examples of such ion-neutral coupling suffer from several shortcomings:

1. The satellite did not image the upper mesosphere in conjunction with these observations, so the coupling from the upper mesosphere to the lower thermosphere could not be directly observed or quantified.

2. The modeling capabilities and weather-satellite imagery available in the DE-2 era were inadequate to relate the observations to terrestrial weather events.

3. The very short duration of the DE-2 mission once the orbit dropped below the ionospheric F-peak made it impossible to assess seasonal, spatial, and local time variations in the coupling patterns.

The LAICE CubeSat mission will overcome all of these obstacles, thereby enabling a global synoptic study of terrestrial weather system effects on the conductive ionospheric medium.

\section{Material and Methods}

LAICE will measure ionospheric plasma density and temperature in-situ via the retarding potential analysis (RPA) technique. The RPA is one of the oldest and most thoroughly flightproven space instruments with over 40 years of successful missions, including: AE, DE, DMSP, ROCSAT, and C/NOFS. The upper atmospheric neutral gas density will be measured in-situ by two distinct sensors: the LAICE Ionization gauge Neutral Atmosphere Sensor (LINAS), and the newly developed Space Neutral Pressure Instrument (SNeuPI) that utilizes a microtip emitter as its ionization source, and a microchannel plate as a detector. LINAS is conventional BayardAlpert type gauge that consumes too much power to be run continuously on a CubeSat. It is a flight-proven instrument that has been scaled down for accommodation on the LAICE mission, while SNeuPI is a technology demonstration prototype sensor that makes a similar measurement, but requires less power and mass. If successful, SNeuPI will be ideally suited to future CubeSatsized missions. Together these two gauges comprise the Space Pressure Suite (SPS).

Mesospheric gravity wave parameters will be measured by a suite of nadir-viewing photometers that observe the $\mathrm{O}_{2}(0-0)$ Atmospheric $\left(\mathrm{O}_{2}\right.$ A) and $\mathrm{O}_{2}$ Herzberg $\mathrm{I}\left(\mathrm{O}_{2} \mathrm{HI}\right)$ band airglow emissions in the $90-100 \mathrm{~km}$ region during the nighttime portion of the orbit. The photometer will only be operated at night, and will be powered down during the daytime portion of the orbit. The photometer array measures airglow perturbations in the $\mathrm{O}_{2}$ A layer with a coarse linear array (4 pixels), and with a single pixel in $\mathrm{O}_{2} \mathrm{HI}$. With these airglow measurements the intrinsic wave parameters are determined: horizontal and vertical wavelengths, and amplitude for horizontal components $>30 \mathrm{~km}$ in the orbital plane. Two additional photometer channels are also utilized: an $\mathrm{O}_{2} \mathrm{~A}$ band channel with an offset wavelength for mesospheric temperature calculations and an $\mathrm{O}_{2} \mathrm{~A}$ background channel for calibration.

\subsection{RPA Instrument}

Mechanically an RPA is simply a series of finely woven wire mesh grids in a stacked planar configuration between an aperture grid and a solid planar collector. The collector and all but one of the grids are held at constant (but different) potentials, and the non-constant (retarding) grid voltage is swept over a range of positive values from spacecraft ground through about +12 volts. The normal to the aperture plane points in the ram direction, and as the satellite flies the RPA collects ambient thermal ions, which enter the aperture supersonically due to the satellite's high 
velocity. Ions with sufficient energy to overcome the retarding voltage are collected, the rest are repelled. An image of the LAICE RPA sensor is shown in Figure 2.

The total current to the collector is plotted as a function of the retarding voltage to produce IV curves like the one shown in Figure 3. These curves are analyzed to infer the ion temperature, ion density, light/heavy ion composition ratio, and the component of the ion velocity in the direction parallel to the satellite's motion. Data quality from the LAICE mission should be similar to the data shown in this figure, but the IV curves will be representative of the lower altitude domain sampled by LAICE (i.e. little or no H+, but with added contributions from molecular ions found at lower altitudes). The basic RPA design, the techniques used for IV curve fitting, the resulting uncertainties, and the general operation of RPA devices have been well documented in the literature over more than half a century (Whipple, 1959; Knudsen, 1966; Hanson et al., 1981; Chou et al., 2003; Klenzing et al., 2008; Davidson and Earle, 2011).

The primary science measurements provided by the LAICE RPA are variations in plasma density and ion temperature associated with wave-induced vertical motions in the ionosphere. The spatial resolution of the RPA is determined by the time taken to perform a complete voltage sweep on the retarding grid. For LAICE, we will obtain a complete high-resolution retarding voltage sweep every second, resulting in a horizontal spatial resolution of $\sim 8 \mathrm{~km}$. This is ample for our mission science requirements, since it corresponds to 25 or more discrete samples over a horizontal gravity-wavelength scale of $200-400 \mathrm{~km}$, which is typical for gravity waves capable of reaching F-region altitudes (Earle et al., 2008; Vadas and Nicolls, 2012).

\subsection{SPS}

Variations in the in-situ neutral pressure will be measured by the Space Pressure Suite (SPS). SPS consists of two sensors: the LAICE Ionization gauge Neutral Atmosphere Sensor (LINAS) and the Space Neutral Pressure Instrument (SNeuPI). Both sensors will be housed in a single baffled box with one aperture to admit the neutral gas to be measured. The aperture is vacuumsealed at launch and opened to space after satellite deployment. The vacuum seal is intended to keep dust and water vapor from contaminating the sensors prior to launch.

A cut-away view showing the mechanical configuration of the SPS is shown in Figure 4, and a photograph of a mechanical prototype of the aperture cover mechanism is shown in Figure 5. In Figure 4 the chamber for the traditional BA gauge is on the left, while the chamber on the right houses the SNeuPI design. A baffle between the two sides of the SPS ensures that both chambers will experience the same pressure variations, but will not allow the gauges to interact with one another.

The SPS will measure the neutral pressure at a $1 \mathrm{~Hz}$ rate, providing $\sim 8 \mathrm{~km}$ spatial resolution at pressures down to $10^{-7}$ Torr. Once the cover opens in flight, the normal to the SPS aperture will point in the ram direction (along the velocity vector of the satellite). This will ensure a steady stream of neutral gas into the aperture, and the ram effect at orbital velocities will increase the internal chamber pressure by a factor of $\sim 12$ relative to the ambient gas in the space environment. Since the purpose of the SPS is to measure relative fluctuations in the neutral gas due to gravity waves, this ram orientation is advantageous because it increases the signal to noise ratios of both SPS sensors. 
The vacuum sealed cover over the SPS aperture cannot be jettisoned due to restrictions on deployment from CubeSats. Since this cover will remain attached to the satellite, the bus design has the cover deploying in the nadir direction. The additional drag introduced by the cover after it opens will therefore result in a slight but continuous torque in the pitch down direction. This force will be partially offset by other torques, including those from antenna elements and stabilization fins.

\subsubsection{SNeuPI Instrument}

The Space Neutral Pressure Instrument (SNeuPI) is an element of the SPS that represents the technology demonstration portion of the LAICE mission. By comparing the intermittent measurements from the heritage LINAS sensor with those from SNeuPI we will validate the utility of these low power devices for future space use (e.g., in neutral wind meters and/or neutral mass spectrometers). Filament lifetime tests in oxygen at Virginia Tech have shown that the thoria-coated iridium filaments of the type used in SPS can survive in oxygen for well over 13,000 cycles in this operating mode, which is more than sufficient to establish the validity of the SNeuPI sensor over the 9-12 month mission lifetime. SNeuPI will measure neutral pressure variations with the high spatial resolution required to identify gravity waves in the thermosphere at F-region altitudes, while simultaneously validating the new gauge design for space-based neutral gas measurements.

Figure 6 shows the results of a SIMION ${ }^{T M}$ study to validate the SNeuPI instrument concept. The figure shows a stream of energetic electrons emanating from a microtip emitter array (left side). The electrons that have sufficient energy to ionize the atmospheric neutrals in the chamber are depicted by the blue and green segments of the trajectory plots. The potential distribution in the chamber effectively deflects these electrons back toward the grounded walls, where they are collected. The ionized neutrals within the chamber (black traces) are attracted to the large negative potential on the microchannel plate, which is shown on the right side of the figure.

The SNeuPI instrument will be run in one of two modes:

1. Constant current electron emission mode;

2. Swept emission current mode.

In the constant emission mode a control circuit continuously adjusts the microtip emitter voltages to maintain a constant current with a slowly varying energy distribution. In the swept current mode the emitters will be sequentially run at several discrete emission levels. This approach is designed to help understand how the emitters age/degrade when subjected to the high percentages of monatomic oxygen encountered in LEO.

\subsubsection{LINAS Instrument}

The LINAS instrument is the latest in a long line of pressure sensors that have been flown in space for scientific purposes (Spencer and Dow, 1954; Moe and Moe, 1967; Hecht et al., 2004). It is based on The Aerospace Corporation's Ionization Gauge Sensor (IGS) design, in particular the IGS design flown on the STREAK satellite mission (Clemmons et al, 2009). LINAS consists of the ionization gauge, electronic controller board, and associated cabling.

The LINAS instrument measures the variation in the in-situ neutral pressure by utilizing a Cannon Corp. MG-2 Bayard-Alpert ionization gauge, which is a hot-filament ionization gauge 
that is routinely used to make laboratory pressure measurements in vacuum chambers. The LINAS gauge operates by partially ionizing a volume of gas using a stream of electrons, and then measuring the current resulting from the ions collected by the biased collector. The density of the gas within the accommodation chamber is proportional to the ratio of the collected ion current to the ionizing electron current. From the pressure data, the neutral temperature may also be calculated. What makes LINAS a thermospheric sensor and not merely a standard ionization gauge commonly used in laboratories, is the high resolution, high performance measurements made by state-of-the-art electronics. A functional block diagram of the sensor is shown in Figure 7.

In order to meet the size limitations of a CubeSat, the original IGS electronic controller board design required several modifications. These include replacement of obsolete parts, removal of unneeded features (stepping voltage, chamber screen), miniaturization of connectors, and a repackaged electronics board for a $1 \mathrm{U}$ CubeSat form factor. The subsequent size of the board is $10.160 \times 8.664 \mathrm{~cm}$ and the expected power required is $3.65 \mathrm{~W}$. For the LAICE mission, LINAS is required to measure pressures over the $400-150 \mathrm{~km}$ altitude range $\left(10^{-7}\right.$ Torr to $10^{-4}$ Torr, respectively). Because of the large pressure range, a dual range capability has been built into the electronics by an auto-range function within an FPGA.

Because of the high power requirement for LINAS, the sensor will be operated on a reduced duty cycle. The primary objective of the sensor is to provide calibration and validation of the SNeuPI pressure sensor with a secondary objective of providing limited science data. Although the sensor's sampling rate is $0.5 \mathrm{msec}$, the controller board will average the samples and produce a single data point every $1 \mathrm{sec}$ that is synchronized to the data collection rate of SNeuPI. The reduction in data sampling is also necessary due to the limited on-board data storage and telemetry downlink.

\subsection{Photometer Instrument}

The photometer instrument for LAICE is designed with 4 optical channels: two to observe the nighttime $\mathrm{O}_{2}(0,0)$ Atmospheric band, one on the $\mathrm{O}_{2}$ Herzberg I band, and a background channel related to the $\mathrm{O}_{2} \mathrm{~A}$ emission. Two of these channels are shown in Figure 8 for $\mathrm{O}_{2} \mathrm{~A}$ and $\mathrm{O}_{2} \mathrm{HI}$ bands. The sensors consist of 7 photon-counting photomultiplier tubes (PMT) from Hamamatsu. These PMTs are low-noise sensors and do not require cooling to achieve science data goals. Though the photometer will only be powered-on during the eclipse portion of the orbit, an overlight signal from the sensors be used to power them off in case of excessive light exposure.

The photometer optics utilize narrow-band $(1 \mathrm{~nm})$ filters to measure the $\mathrm{O}_{2} \mathrm{~A}$ band with center wavelengths at 763.5 and $765.5 \mathrm{~nm}$. To observe the $\mathrm{O}_{2} \mathrm{HI}$ band, a broadband filter with a transmission range from $255-299 \mathrm{~nm}$ is utilized. A narrow-band $(2 \mathrm{~nm})$ filter at $770 \mathrm{~nm}$ will also be used to measure the background relevant to the $\mathrm{O}_{2} \mathrm{~A}$ band emission for calibration purposes. The $\mathrm{O}_{2} \mathrm{~A}$ channel at $763.5 \mathrm{~nm}$ will be equipped with a coarse 4-pixel linear array, comprised of 4 PMT sensors fiber-coupled to the focal plane. With this approach, the photometer will make four measurements across a field of view perpendicular to the orbit plane. Each pixel has a field of view of $2.3^{\circ}$ (or $8 \mathrm{~km}$ footprint from $300 \mathrm{~km}$ altitude), and pixels are spread across a $12^{\circ}$ total field of view $(44 \mathrm{~km})$. A photometer sampling rate of $1 \mathrm{~Hz}$ produces a $\sim 8 \mathrm{~km}$ elongation of the measurement along the orbital track, which combined with the $8 \mathrm{~km}$ footprint gives a sampling rms resolution of $\sim 11.2 \mathrm{~km}$. This is sufficient for measurement of waves with horizontal wavelength $>30 \mathrm{~km}$. This implementation provides horizontally resolved data on GWs, allowing 
the calculation of horizontal orientation of wave-fronts and horizontal wavelengths. Vertical wavelengths will be measured from the phase difference between common volume $\mathrm{O}_{2} \mathrm{~A}$ and $\mathrm{HI}$ band emission measurements, as the centroid heights of their respective volume emission layers are separated by $\sim 3 \mathrm{~km}$ in altitude. Wave amplitudes are determined from the brightness perturbation of wave measurements, which are directly related to their amplitudes. For large vertical wavelengths, the I'/I airglow perturbations are $\sim 4 \mathrm{x}$ the wave amplitude (Liu and Swenson, 2003). The common volume $\mathrm{O}_{2} \mathrm{~A}$ measurements at 763.5 and $765.5 \mathrm{~nm}$ provide mesospheric temperature measurements using the method described by Zhao et al. (2005) for $\mathrm{O}_{2}$ A band (0,1).

The wave spectra of interest at mesospheric altitudes are large amplitude GWs (A>10\%) with horizontal wavelengths $>30 \mathrm{~km}$ and vertical wavelengths $>10 \mathrm{~km}$. It is the $30+\mathrm{km}$ vertical wavelengths which are particularly important for the science objectives as they have the vertical group velocities to propagate well into the upper thermosphere. Also, planar wave packets (5+ consecutive waves) with $\mathrm{A}>2 \%$ and similar wave spectra will also be measured. Measurements coincident with ground-based observations obtained during observatory fly-overs will provide calibration and validation data regarding the intrinsic parameters of the GWs observed by LAICE. Although perturbations are produced by both waves and instabilities, the spatial scales of instabilities are smaller than the sensing footprint of these photometers.

\section{4. $6 U$ CubeSat Bus}

The LAICE mission uses the Illinisat-2 generic scalable picosatellite bus as its platform to support the four scientific instruments. The Illinisat- 2 bus can adapt to most common CubeSat form factors, from as small as $1.5 \mathrm{U}$ up to $6 \mathrm{U}$. A model of the 6U LAICE CubeSat is shown in Figure 9.

The service module supplies command and data handling, communications, power management, and attitude control functions in a volume of only $0.75 \mathrm{U}$, leaving all remaining mass and volume to be dedicated to payloads. The photometer payload, which consists of the PMT sensors, optical assemblies, and payload control boards, requires approximately $3 \mathrm{U}$ of volume. The in-situ sensing payload, consisting of the RPA, SPS, and associated electrometer, sweep voltage, and bias control boards requires approximately $2 \mathrm{U}$ in volume. These large volumetric requirements of the payload necessitated the $6 \mathrm{U}$ form factor (taking a volume of $22.6 \times 36.6 \times 10.0 \mathrm{~cm})$. Table 1 gives an overview of the LAICE mission. Note that the LAICE satellite is nominally $9 \mathrm{~kg}$, and the margin will be consumed prior to launch with any necessary ballast mass to bring it up to $12 \mathrm{~kg}$ to increase the satellite's ballistic coefficient and hence increase mission lifetime in LEO.

\subsubsection{Structure}

The Illinisat- 2 structure is primarily aluminum, and its main structural members are a series of three plates and six rails, to which all other components are attached. The design is meant to be easy to assemble and highly modular. All satellite bus equipment attaches to the aft service plate. The RPA/SPS payloads attach to the ram-facing payload plate. The photometer payload attaches to the nadir-facing plate. The bus electronics boards are mounted to each other to form the service stack, which is attached to the aft service plate for thermal conductivity, as this plate also acts as the satellite radiator. The solar panel structural members are made of carbon fiber, rendering the panels extremely light and somewhat flexible while capable of surviving vacuum and vibration. 


\subsubsection{Power}

The Illinisat-2 power management system can scale to support from four to six solar panels that can be from 1.5 to $3 \mathrm{U}$ long. In the case of the LAICE mission, five panels will be flown with 8 solar cells each, leading to an expected orbit average power ranging from 3 to $12 \mathrm{~W}$. This variance is dependent on the orbit beta angle to the sun, as the satellite needs to retain a specific, non-sun tracking orientation for the science operation. Onboard energy storage is provided by a lithium-ion battery pack, comprised of four lithium-ion cells.

\subsubsection{Command and Data Handling}

The command and data handling $(\mathrm{C} \& \mathrm{DH})$ embedded computer on the IlliniSat-2 bus is a COTS system-on-module connected to the C\&DH service board, which is connected to all the satellite subsystems through a variety of serial ports. It is equipped with a Cortex-A8 $1 \mathrm{GHz}$ processor that runs a customized Linux distribution, and the flight software runs on this Linux operating system. The C\&DH board also contains primary storage memory, along with redundant memory for booting and data storage. The flight software subroutines are run as Linux daemons and are responsible for enforcing the mission schedule, managing spacecraft subsystems and data, and monitoring satellite health. The flight software subroutines are as follows:

- Scheduler - maintains mission schedule in flight and enforces all uplinked commands

- Payload readers - communicates with the payloads according to their specified communication protocols, time tags the payload data, stores it for future downlink

- Health monitor - receives subsystem housekeeping data from other daemons, detects anomalies and corrects them

- Radio controllers - packages all science and housekeeping data with checksums, coordinates downlink, receives uplink and processes them for new commands and files

- ADCS interface - communicates with the ADCS software and sensors/actuators (magnetometers and torque coils), and updates the ephemeris data received from the ground

- Power board interface - coordinates with the power board to switch on/off power supply to all other subsystems, logs power board housekeeping data for later downlink, and monitors battery charge level, putting LAICE into a charging mode as needed

\subsubsection{Communication}

The Illinisat- 2 bus uses a Lithium-2 amateur band radio operating at 9600 baud as its preferred method for housekeeping and command uplink and downlink, and both the University of Illinois and Virginia Tech have compatible ground stations. Also, this radio provides a beacon for initially locating the satellite. The amount of data generated by the LAICE mission necessitates a higher speed radio, as the mission lifetime is limited due to the low orbit, and reentry will occur before the amateur band could downlink all the data. To fulfill this high speed data requirement, a second radio, the Cadet by L3 Communications is also flying on board. This radio will be operated at $3 \mathrm{Mbps}$, and will communicate with a ground station at the Wallops Flight Facility.

\subsubsection{Attitude Determination and Control}


The Illinisat-2 bus uses a magnetic attitude determination and control system. A set of 3-axis magnetometers produce a single magnetic field reference vector using a sensor fusion voting algorithm. A Kalman Filter method is used to determine the attitude, attitude rates, and disturbance torques and is capable of determining attitude to within $0.06^{\circ}$ (Martel et al., 1998). Errors in the IGRF model and ephemeris will increase the attitude determination uncertainty. Electromagnetic coils embedded in the solar panels and in the service stack provide attitude control by generating a magnetic moment which torques the spacecraft against the Earth's local magnetic field. The control torque is determined using quaternion feedback control (Wie, 2006). Special consideration is made to ensure that the magnetic moment generated to provide the desired torque is perpendicular to the local magnetic field to maximize power efficiency of the maneuver.

An example simulation of the quaternion rate feedback method reduces the attitude rates and errors from a random initial orientation and attitude rate of $5 \% \mathrm{sec}$ (worst case attitude rate upon deployment) and converges to within $0.57^{\circ}$ within 2.5 hours. The simulated controller used a 10 second close-loop duty cycle with a 0.45 second dead-band in actuation to replicate the duration for collecting magnetometer readings. The magnetic torque coils were simulated to have 128 discreet output levels. This simulation demonstrates the attitude control authority needed for the LAICE mission.

\section{Calculation}

The performance characteristics of the LAICE payload instruments have been simulated to compare with the science goals of the mission.

\subsection{Photometer Payload}

Table 2 provides an overview of the signal characteristics of the LAICE photometer. The S/N ratios for the $\mathrm{O}_{2} \mathrm{HI}$ and $\mathrm{O}_{2} \mathrm{~A}$ linear array are 198 and 99, respectively with a $1 \mathrm{~Hz}$ sampling rate, providing $\sim 1 \%$ I'/I brightness measurement error, meeting the primary objectives for observing large waves or bores (LWBs, $\mathrm{A}>10 \%$ or I'/I $>40 \%$ ) and planar wave packets (PWPs, $\mathrm{A}>2 \%$ or I'/I>8\% with observation of 5+ waves). The goals for measurement of gravity wave intrinsic parameters are to determine LWB wave amplitudes to $3 \%$ precision, PWP wave amplitudes to $10 \%$, mesospheric temperature within $3 \%$, and to determine horizontal and vertical wavelengths within $10 \%$. Calculation of horizontal wavelengths also requires determination of horizontal wave-front orientation to within $15^{\circ}$, and this capability is provided by the 4-pixel linear array.

The performance calculations in Table 3 show that LAICE will determine amplitudes of large-amplitude waves with $\mathrm{S} / \mathrm{N}>79$, a margin of $>2 \mathrm{x}$ the sensitivity threshold required. For

planar wave packets, amplitudes can be determined with $\mathrm{S} / \mathrm{N}>35$, also $>2 \mathrm{x}$ margin. Calculation of GW wavelengths to $10 \%$ precision is also performed which are also within margin. The 4pixel PMT channel also provides horizontal orientation of the wave-front to within $3^{\circ}$. In addition, airglow layer temperatures can also be obtained to $\sim 1 \%$ precision or $\pm 2 \mathrm{~K}$.

\subsection{Photometer Simulation}

The data obtained from the photometer linear array can be simulated by use of airglow imagery taken at a ground-based observatory. Figure 10 shows an $\mathrm{OH}$ airglow image, taken on Jan 24, 2012 at the Andes Lidar Observatory (ALO). In this image, several waves can be seen, with wavefronts oriented roughly parallel to each other. The galactic background can also be seen, which extends diagonally through the image from the upper left to lower right. The 4 tracks 
of the 4-pixel PMT array are shown in red (selected to avoid the galactic background), with the first footprint in each track indicated with 2 circles (beginning and end of first data point over a 1 -second integration). The tracks are $12 \mathrm{~km}$ wide, which is the PMT footprint from a $400 \mathrm{~km}$ orbit. The tracks as shown contain 40 data points in each track.

The simulated PMT data are plotted in Figure 11, normalized to the mean intensity in the image. In this figure, 2 waves can be clearly identified, with brightness amplitudes calculated at $5 \%$ and $20 \%$, respectively. Assuming a $4 \mathrm{x}$ amplification factor, the actual wave amplitudes are $1.3 \%$ and $5 \%$. Horizontal wavelengths are calculated to be $90 \mathrm{~km}$ and $130 \mathrm{~km}$, respectively. The horizontal wavefront orientations are determined to first order by using the phase difference between the two outer tracks, and are calculated to be $25^{\circ}$.

\subsection{RPA/SPS Performance}

Figure 1 shows an example of gravity wave-induced perturbations in the lower thermosphere at high mid-latitudes, as measured by instrumentation aboard the DE-2 satellite. The top two panels of the figure show the ion and neutral density perturbations measured by the satellite in the lower thermosphere, which are similar to the measurements that LAICE will make using the two SPS instruments in conjunction with the retarding potential analyzer. Earle et al. (2008) show that these wave-like signatures are consistent with theoretical expectations for gravity waves propagating upward from the mesosphere. The dominant wavelengths projected along the orbit track appear to be in the 400-600 km range, and the complex nature of the waveforms suggests that they result from the interaction of several different waves. Earle et al. (2008) show that such perturbations are likely related to gravity waves having periods near 30 minutes, and vertical displacement amplitudes near $6 \mathrm{~km}$.

Although the LAICE mission will not measure the vertical plasma and neutral motions, the density perturbations arising from vertical motions of the ions and neutrals due to gravity waves will be observable with the RPA and SPS instruments. The former is a scaled-down instrument that is similar to the DE-2 RPA in mechanical form, but somewhat different electronically due to its uplink-controllable sweep modes and logarithmic electrometer. The SPS instrument includes two ion gauges; one has heritage from the STREAK-1 mission (Clemmons et al., 2008), and the second is a new cold cathode-based design. Together the LAICE RPA and SPS instruments will be capable of measuring wave-induced plasma and neutral density variations in the lower thermosphere similar to those shown in the top two panels of Figure 1. The improved electronics available in the modern era will allow over-sampling and averaging to be performed in an FPGA that controls the RPA. This will allow higher fidelity measurements than those obtained by the DE-2 RPA.

The simulated performance of the RPA and SPS instruments is given in Table 4. The electrical characteristics of the LAICE RPA compare favorably to the DE-2 instrument, but there are some important differences. The most critical comparison relates to the electrometer that measures the collected current as a function of the retarding voltage applied to the discriminator grid. On DE-2 the electrometer was a linear-ranging device, while on LAICE we have opted for a logarithmic electrometer. The logarithmic design sacrifices some sensitivity on the high current side, but is more sensitive to small current fluctuations. The instrument aperture is also larger on LAICE than it was on DE-2, so LAICE will measure larger currents for a given plasma density. This change is appropriate since LAICE will fly at a lower altitude than at which the bulk of the DE-2 mission data were taken. 
LAICE will perform one sweep of the RPA retarding voltage per second, while the DE-2 RPA had a variable sweep rate that ranged from 300-700 ms. Consequently the DE-2 instrument had slightly better spatial resolution than what will be obtained on LAICE for the ion measurements. In contrast, the WATS instrument on DE-2 required several seconds for each neutral gas pressure measurement, while the two SPS instruments will each make one measurement per second. Consequently the LAICE mission should obtain improved spatial resolution in the neutral measurements relative to the neutral data shown in Figure 1. In summary, the most significant differences between the LAICE instrumentation and those of DE2 include:

1. LAICE uses modern components along with smaller circuit boards, chip resistors, and surface mount parts to reduce the size of the electronics box and the overall power requirement.

2. The LAICE in-situ instruments are driven by FPGAs that control the instrument operating modes, and implement over-sampling and averaging to improve signal to noise ratios.

3. The LAICE RPA has several non-uniform sweep modes, so that data points can be clustered in critical retarding voltage ranges to improve the accuracy of ground-based curve-fitting analysis.

\section{Discussion}

As the LAICE science mission begins, the accumulating in-situ and remotely sensed datasets will be available for addressing our key science questions. These data will be examined and specific times of interest identified for detailed modeling studies. Our selection criteria will emphasize datasets from different seasons, and will focus on times in which quasi-sinusoidal oscillations with similar periods are seen in the mesospheric airglow, thermospheric pressure, and ionospheric plasma density. Since the satellite measurements are simultaneous, the waves in the mesosphere and thermosphere/ionosphere will be different, although they may be different spectral components from the same source. Preference in data selection for modeling studies will be given to time periods that coincide with fly-overs of ground-based facilities such as Jicamarca, Arequipa, and Arecibo, from which additional data may be available. Where possible we will coordinate campaigns with ground-based observatories to increase the scope of the datasets. Overflights of Arecibo, Jicamarca, and various ionosondes will be also used to crosscheck and validate the in-situ plasma density sensor (RPA). Overflights of ground-based optical sites can be used to validate the LAICE photometer data. These comparisons with ground-based observations will be done whenever the data are available for comparison.

After identifying time intervals of particular interest in each season, we will look for occurrences of deep convection a few hours earlier and located within $20^{\circ}$ in latitude and longitude of the measurement locations. For these cases we will identify the likely convection on IR satellite meteorology images and determine the convective plume parameters from publiclyavailable meteorological data (e.g., Vadas and Liu, 2009, 2013; Vadas and Crowley, 2010; Vadas et al., 2014). The GW modeling approach will be similar to earlier studies (Vadas and Liu, 2009; Vadas et al., 2012). We will model the gravity waves excited by these storms using our convective plume model (Vadas and Fritts, 2009), and we will ray-trace these gravity waves into the mesosphere and thermosphere using our ray-trace model (Vadas and Fritts, 2005, 2006, 2009). We will then calculate the secondary gravity waves excited by the body forces and 
heating/cooling created where these waves dissipate (Vadas and Crowley, 2010), and ray-trace these secondary gravity waves to higher altitudes. Finally, we will compare our model results with the observed waves from LAICE data to see if these convective sources are the likely sources of these waves.

Due to the time delays and horizontal propagation associated with upward propagation of GWs, these factors must be taken into account in our analyses. We will look for the fast primary GWs in the mesosphere (with phase speeds of $\sim 100 \mathrm{~m} / \mathrm{s}$ ) that dissipate at $\sim 200 \mathrm{~km}$ altitude, thereby creating the accelerations that excite secondary GWs that propagate to the thermosphere. The time it takes for primary GWs to create the secondary GWs at $\sim 200 \mathrm{~km}$ altitude is approximately 1.25-1.5 hours, and it takes another hour for these GWs to reach the thermosphere. So the total time from deep convection to reaching 400-500 km altitude is $\sim 2.5$ hours. The horizontal displacement can be determined from the GW dispersion relation (Fritts and Alexander, 2003). For a 20 minute wave and an average buoyancy frequency of 10 minutes, there is a 1:2 aspect ratio, meaning that from the mesosphere to $400 \mathrm{~km}$ (about $300 \mathrm{~km}$ ), the wave would travel $600 \mathrm{~km}$ horizontally. The primary waves observed in the mesosphere can therefore be observed in the thermosphere by the in situ sensors in subsequent orbits as LAICE passes over the same region, accounting for propagation time and horizontal displacement. Since the waves may persist for several hours, this approach can be used to observe wave coupling, as long as the horizontally displaced waves are observable along the orbital path of LAICE.

For modeling studies based on LAICE observations, we will choose from the GW events instances in which GWs do not coincide with active magnetic storms, in order to distinguish GWs sourced from deep-convection with those from geomagnetic activity. To investigate deep convective sources, we will analyze data from latitudes up to 40 degrees during low Kp conditions, when geomagnetic storms had not occurred within the prior 3 days. Also, because GWS that are geomagnetically-generated or excited by the solar terminator have very long periods, we will analyze gravity waves having periods less than an hour. The spectral characteristics of the primary GWs we wish to observe in the mesosphere will have $\lambda_{\mathrm{h}}=50-200$ $\mathrm{km}$, and $\tau=5-30 \mathrm{~min}$. For secondary waves in the thermosphere, we will focus on $\lambda_{\mathrm{h}}=300$ $10000 \mathrm{~km}$, and $\tau=15-60 \mathrm{~min}$. It should be noted however that coupling of waves observed in the mesopause region will have intrinsic attributes which can be ray-traced to higher altitudes, taking into account viscosity and diffusion enroute, and this ray-tracing can be accomplished regardless of the GW sources. LAICE mission data will be available for additional coupling studies and GW analyses by the community.

We will also use the LAICE mission data to study general wave propagation characteristics. For example, in an average sense the gravity wave amplitudes from deep convection should be smaller in the winter than in the summer hemisphere, however waves from mountain wave breaking should be more prevalent in the winter hemisphere, but will be concentrated near mountain ranges. Additionally, gravity waves from deep convection events should generally have a strong local time dependence that follows the meteorological local time variations of the storm sources. Furthermore, as the satellite descends in altitude the along-track horizontal wavelengths of the perturbations should generally decrease due to the altitude influence on propagation characteristics (Vadas, 2007). Finally, at higher altitudes (early in the mission) LAICE will sample secondary gravity waves, while at lower altitudes we will sample both primary (from the lower atmosphere) and secondary gravity waves, which theory predicts will 
have measurable differences in their spectral properties (Vadas and Crowley, 2010). These more general studies will help to validate the models, and will provide additional confidence in the cause-and-effect relationships revealed by the datasets.

Gravity waves may be encountered at almost any latitude over the altitude ranges covered by LAICE (up to $\sim 400 \mathrm{~km}$ ), but part of the goal of the experiment is to obtain enough observations to help illuminate the global distribution of GW activity at these altitudes. The DE-2 measurements of GWs only witnessed them at high mid-latitudes and altitudes below $300 \mathrm{~km}$, but the satellite only spent a few weeks at these low altitudes before reentry, so it is not clear whether its observations are truly representative of GW distributions around the globe. It is possible that the number of tropospheric GWs that reach altitudes greater than $300 \mathrm{~km}$ is very small, as suggested by the DE- 2 results. In that case the photometers should see much more GW activity than the in-situ instruments, at least until the LAICE orbit decays to the $300 \mathrm{~km}$ range and below. One of the objectives of the LAICE mission is to determine whether such waveinduced thermospheric perturbations are also present at lower latitudes, and whether they show any correlation to terrestrial thunderstorms or other systems that could generate primary gravity waves through convective upwelling.

\section{Conclusions}

The LAICE mission is the first mid-inclination satellite to combine remote and in-situ observations of plasma and neutral variations in the lower thermosphere, so it should reveal a great deal about the prevalence, amplitudes, wavelengths, and spatial distributions of gravity wave activity. The capabilities of the LAICE satellite will also address a significant number of other fundamental space-science questions. In particular, LAICE should garner low-altitude plasma and neutral observations of spread-F irregularities in the nighttime equatorial region, and it should augment the Streak-1 observations of global-scale neutral pressure striations aligned with the geomagnetic field (Clemmons et al., 2008). These observations will contribute to our understanding of plasma and neutral dynamics at horizontal spatial scales ranging from $\sim 10 \mathrm{~km}$ to many thousands of kilometers. If the lifetime of the LAICE mission is on the order of 12 months, the longitudinal precession rate should be sufficient to characterize all of the observed effects as functions of season. Thus the LAICE mission is poised to make several important contributions to our understanding of ion and neutral dynamics in the lower thermosphere.

\section{Acknowledgements}

The LAICE CubeSat mission is funded by NSF grant AGS-1242898. The launch for LAICE is funded by NASA's Educational Launch of Nanosatellites initiative (ELaNa). We would also like to acknowledge the contributions of the many undergraduate and graduate students at Virginia Tech and University of Illinois who worked on developing the LAICE CubeSat.

\section{References}

Bauer, S. J. An apparent ionospheric response to the passage of hurricanes. J. Geophys. Res., 63, 265, 1958.

Bishop, R. L., Aponte, N., Earle, G. D., Sulzer, M., Larsen, M. F., Peng, G. S. Arecibo observations of ionospheric perturbations associated with the passage of Tropical Storm Odette. J. Geophys. Res. 111, A11320, 2006.

Chou, C. K., Su, S.-Y., Yeh, H. C. Grid effects on the derived ion temperature and ram velocity from the simulated results of the retarding potential analyzer data. Adv. Space Res., 32, 2361, 2003. 
Clemmons, J. H., Hecht, J. H., Salem, D. R., Strickland, D. J. Thermospheric density in the Earth's magnetic cusp as observed by the Streak mission. Geophys. Res. Lett., 35, L24103, 2008.

Clemmons, J. H., Friesen, L. M., Katz, N., Ben-Ami, M., Dotan, Y., Bishop, R. L. The ionization gauge investigation for the Streak mission. Space Sci. Rev., 145, 263, 2009.

Davidson, R. L., Earle, G. D. A design approach for improving the performance of single-grid planar retarding potential analyzers. Phys. Plasmas 18, 012905, 2011.

Earle, G. D., Musumba, A. M., Vadas, S. L. Satellite-based measurements of gravity waveinduced midlatitude plasma density perturbations. J. Geophys. Res. 113, A03303, 2008.

Earle, G. D., Bhaneja, P., Bullett, T. W., Bishop, R. L., Redmon, R. A comprehensive rocket and radar study of midlatitude spread F. J. Geophys. Res., 115, A12339, 2010.

Farrell, W. M., Aggson, T. L., Rodgers, E. B., Hanson, W. B. Observations of ionospheric electric fields above atmospheric weather systems. J. Geophys. Res., 99, 19,475, 1994.

Fritts, D., Alexander, M. Gravity wave dynamics and effects in the middle atmosphere. Reviews of Geophys., 41, 1/1003, 2003.

Hanson, W. B., Zuccaro, D. R., Lippincott, C. R., Sanatani, S. The retarding-potential analyzer on Atmosphere Explorer. Radio Sci., 8(4), 333-339, 1973.

Hanson, W. B., Heelis, R. A., Power, R. A., Lippincott, C. R., Zuccaro, D. R., Holt, B. J., Harmon, L. H., Sanatani, S. The retarding potential analyzer for Dynamics Explorer B. Space Sci. Instrum., 5, 503, 1981.

Hanson, W. B., Johnson, F. S. Lower midlatitude ionospheric disturbances and the Perkins instability, Planet. Space Sci., 40, 1615, 1992.

Hecht, J. H., Liu, A. Z., Bishop, R. L., Clemmons, J. H., Gardner, C. S., Larsen, M. F., Roble, R. G., Swenson, G. R., Walterscheid, R. L. An overview of observations of unstable layers during the Turbulent Oxygen Mixing Experiment (TOMEX). J. Geophys. Res., 109, D02S01, 2004.

Heelis, R.A., Hanson, W. B., Lippincott, C. R., Zuccaro, D. R., Harmon, L. H., Holt, B.J., Doherty, J. E., Power, R. A. The Ion Drift Meter for Dynamics Explorer-B. Space Sci Instr., 5, 511-521, 1981.

Hines, C. O. Internal atmospheric gravity waves at ionospheric heights. Can. J. Phys., 38, 1441, 1960.

Hocke, K., Schlegel, K. A review of atmospheric gravity waves and travelling ionospheric disturbances: 1982-1995. Annales Geophysicae, 14, 917, 1996.

Hung, R. J., Phan, T., Smith, R. E. Observation of gravity waves during the extreme tornado outbreak of 3 April 1974. J. Atmos. Terr. Phys., 40, 831, 1978.

Klenzing, J. H., Earle, G. D., Heelis, R. A. Errors in ram velocity and temperature measurements from satellite-borne retarding potential analyzers. Phys. Plasmas, 15, 062905, 2008.

Knudsen, W. C. Evaluation and demonstration of the use of retarding potential analyzers for measuring several ionospheric quantities. J. Geophys. Res., 71, 4669, 1966.

Larsen, M. F., Swartz, W. E., Woodman, R. F. Gravity wave generation by thunderstorms observed with a vertically pointing $430 \mathrm{MHz}$ radar. Geophys. Res. Lett., 9, 571, 1982.

Liu, A. Z., Swenson, G. R. A modeling study of $\mathrm{O}_{2}$ and $\mathrm{OH}$ airglow perturbations induced by atmospheric gravity waves. J. Geophys. Res., 108, 4151, 2003.

Liu, H.-L., Vadas, S. L. Large-scale ionospheric disturbances due to the dissipation of convectively-generated gravity waves over Brazil. J. Geophys. Res. Space Phys., 118, 24192427, 2013. 
Martel, F., Pal, P. K., Psiaki, M. L. Three-Axis Attitude Determination via Kalman Filtering of Magnetometer Data. Flight Mechanics/Estimation Theory Symposium, NASA/Goddard Space Flight Center, 1988.

McClure, J. P. Occurrence of equatorial F region irregularities: Evidence for tropospheric seeding. J. Geophys. Res., 103, 29,119, 1998.

Moe, K., Moe, M. M. The effect of absorption on densities measured by orbiting pressure gauges, Planet. Space Sci., 15, 1329-1332, 1967.

Pierce, A. D., Coroniti, S. C. A mechanism for the generation of acoustic-gravity waves during thunderstorm formation. Nature, 5042, 1209, 1966.

Spencer, N. W., Dow, W. G. Density-gauge methods for measuring upper-air temperature, pressure, and winds, in: Boyd, R. L. F., Seaton, M. J., Massey, H. S. W. (Eds.), Rocket Exploration of the Upper Atmosphere. pp. 82-97, Interscience Publishers, New York, 1954.

Spencer, N. W., Wharton, L. E., Niemann, H. B., Hedin, A. E., Carrignan, G. R., Maurer, J. C. The Dynamics Explorer Wind and Temperature Spectrometer Space Science Instrumentation. 5, 417-428, 1981.

Vadas, S. L., Fritts, D. C. Thermospheric responses to gravity waves: Influences of increasing viscosity and thermal diffusivity. J. Geophys. Res., 110, D15103, 2005.

Vadas, S. L., Fritts, D. C. The influence of solar variability on gravity wave structure and dissipation in the thermosphere from tropospheric convection? J. Geophys. Res., 111, A10S12, 2006.

Vadas, S.L. Horizontal and vertical propagation and dissipation of gravity waves in the thermosphere from lower atmospheric and thermospheric sources. J. Geophys. Res., 112, A06305, 2007.

Vadas, S. L., Liu, H.-L. The generation of large-scale gravity waves and neutral winds in the thermosphere from the dissipation of convectively-generated gravity waves. J. Geophys. Res., 114, A10310, 2009.

Vadas, S. L., Fritts, D. C. Reconstruction of the gravity wave field excited by convective plumes via ray tracing in real space. Annals. Geophys., 27, 147-177, 2009.

Vadas, S. L., Yue, J., She, C.-Y., Stamus, P. A., Liu, A. Z. A model study of the effects of winds on concentric rings of gravity waves from a convective plume near Fort Collins on 11 May 2004. J. Geophys. Res., 114, D06103, 2009.

Vadas, S.L., Crowley, G. Sources of the traveling ionospheric disturbances observed by the ionospheric TIDDBIT sounder near Wallops Island on October 30, 2007. J. Geophys. Res., 115, A07324, 2010.

Vadas, S. L., Nicolls, M. J. The phases and amplitudes of gravity waves propagating and dissipating in the thermosphere: Theory. J. Geophys. Res., 117, A05322, 2012.

Vadas, S.L., Yue, J., Nakamura, T. Mesospheric concentric gravity waves generated by multiple convection storms over the North America Great Plain. J. Geophys. Res., 117, D7, 2012.

Vadas, S. L., Liu, H.-L. Numerical modeling of the large-scale neutral and plasma responses to the body forces created by the dissipation of gravity waves from $6 \mathrm{~h}$ of deep convection in Brazil. J. Geophys. Res. Space Phys., 118, 2593-2617, 2013.

Vadas, S.L., Liu, H.-L., Lieberman, R.S. Numerical modeling of the global changes to the thermosphere and ionosphere from the dissipation of gravity waves from deep convection. J. Geophys. Res. Space Phys., 119, 2014.

Whipple, E. C. The ion-trap results in: Exploration of the Upper Atmosphere with the Help of the Third Soviet Sputnik. Proc. IRE, 47, 2023, 1959. 
Wie, B. Space Vehicle Dynamics and Control 2nd Ed. AIAA, Reston, VA, pp. 402-404, 2006.

Zhao, Y., Taylor, M. J., Chu, X. Comparison of simultaneous Na lidar and mesospheric nightglow temperature measurements and the effects of tides on the emission layer heights. J. Geophys. Res., 110, D09S07, 2005.

\section{Figure Captions}

Figure 1: Perturbations of the plasma and neutral gases in LEO from DE-2 orbit \#8250. The top two panels show ion and neutral density perturbations along the orbit track, respectively, vs. satellite time (bottom axis) and horizontal distance (top axis). The bottom two panels show the vertical component of the plasma and neutral bulk motion.

Figure 2: Image of the RPA for LAICE showing the gold-plated ground plane and gridded aperture

Figure 3: Data from an RPA instrument aboard one of the DMSP satellites in a mixed $\mathrm{O}^{+} / \mathrm{H}^{+}$ plasma

Figure 4: Cut-away view of the internally baffled chamber for the BA and DLC-microtip pressure instruments

Figure 5: Photo of the prototype SPS vacuum cover mechanism in its open configuration

Figure 6: Particle trajectory simulation of the SNeuPI instrument concept. The contour potentials from the left of the MCP up to the emitters are $-1024 \mathrm{~V}$ to $-1 \mathrm{~V}$ in factors of $0.5 \mathrm{x}$.

Figure 7: Flow diagram illustrating the functionality of the LINAS sensor

Figure 8: Two photometer channels for observing $\mathrm{O}_{2} \mathrm{~A}$ and $\mathrm{O}_{2} \mathrm{HI}$ mesospheric airglows

Figure 9: LAICE model showing primary bus systems and payloads

Figure 10: OH airglow image from ALO, with simulated PMT array measurements

Figure 11: Simulated photometer data from $\mathrm{OH}$ airglow image 
Table 1: LAICE mission overview

\begin{tabular}{|l|l|}
\hline Launch & Jan $2016-$ ISS deployment planned \\
\hline Orbit & $\sim 400 \mathrm{~km}$ circ., $51^{\circ}$ inclination \\
\hline Mission lifetime & $>9 \mathrm{months}$ \\
\hline Mass /volume & $12 \mathrm{~kg} / 6 \mathrm{U}$ \\
\hline Power usage & $5.7 \mathrm{~W} \mathrm{OAP}$ \\
\hline Data generation & $320 \mathrm{Mbit} /$ day \\
\hline Link budget & $500 \mathrm{Mbit} /$ day downlink \\
\hline Energy storage & $38.48 \mathrm{~W}$-hr \\
\hline Data storage & $1 \mathrm{~GB} \mathrm{redundant}$ on $\mathrm{S} / \mathrm{C}$ \\
\hline Attitude control & $<10^{\circ}, 3 \sigma, \mathrm{pitch} / \mathrm{yaw} / \mathrm{roll}$ \\
\hline Attitude knowledge & $<5^{\circ}, 3 \sigma, \mathrm{pitch} / \mathrm{yaw} / \mathrm{roll}$, real-time \\
\hline
\end{tabular}

Table 2: LAICE Photometer Signal Characteristics

\begin{tabular}{|c|c|c|c|c|}
\hline Band observed & $\mathrm{O}_{2} \mathrm{HI}$ & $\mathrm{O}_{2} \mathrm{~A}$ & $\mathrm{O}_{2} \mathrm{~A}$ & $\begin{array}{c}\mathrm{O}_{2} \mathrm{~A} \\
\text { (background) }\end{array}$ \\
\hline PMT Sensor & H10682-110 & H10682-01 & H10682-01 & H10682-01 \\
\hline Filter CWL (nm) & 277.0 & 763.5 & 765.5 & 770.0 \\
\hline$Q_{\mathrm{e}}$ at $\mathrm{CWL}$ & $21 \%$ & $1.6 \%$ & $1.6 \%$ & $1.6 \%$ \\
\hline $\begin{array}{l}\text { Total nadir band } \\
\text { brightness (Rayleigh) }\end{array}$ & 600 & 6000 & 6000 & $40+$ \\
\hline Effective band trans. & 0.20 & 0.14 & 0.03 & $\mathrm{n} / \mathrm{a}$ \\
\hline Lens dia. (mm) & 50 & 50 & 50 & 25 \\
\hline $\mathrm{A} \Omega\left(\mathrm{cm}^{2} \mathrm{str}\right)$ & $2.0 * 10^{-2}$ & $2.0 * 10^{-2}$ & $2.0 * 10^{-2}$ & $4.4 * 10^{-3}$ \\
\hline $\mathrm{S} / \mathrm{N}$ ratio (I'/I) & 198 & 99 & 64 & $\mathrm{n} / \mathrm{a}$ \\
\hline
\end{tabular}

Table 3: LAICE Photometer Performance

\begin{tabular}{|l|c|c|c|c|}
\hline Science Requirement & Measurement & $\begin{array}{c}\text { S/N } \\
\text { required }\end{array}$ & $\begin{array}{c}\text { S/N } \\
\text { performance }\end{array}$ & Margin \\
\hline $\begin{array}{l}\text { Determine amplitudes to } \\
3 \% \text { precision (LWB) }\end{array}$ & I'/I & 33 & 79 & $140 \%$ \\
\hline $\begin{array}{l}\text { Determine horiz. and } \\
\text { vert. wavelengths to 10\% } \\
\text { precision (LWB) }\end{array}$ & $\begin{array}{c}\text { vert. and horiz. } \\
\text { Phase }\end{array}$ & 10 & 27 & $170 \%$ \\
\hline $\begin{array}{l}\text { Determine wavefront } \\
\text { orientation within 15 }\end{array}$ & $\begin{array}{c}\text { 4-pixel horiz. } \\
\text { Phase }\end{array}$ & $\sigma<15^{\circ}$ & $\sigma<3^{\circ}$ & $>400 \%$ \\
\hline $\begin{array}{l}\text { Determine amplitude to } \\
10 \% \text { precision (PWP) }\end{array}$ & I'/I & 10 & 35 & $250 \%$ \\
\hline $\begin{array}{l}\text { Determine horiz. and } \\
\text { vert. wavelengths to 10\% } \\
\text { precision (PWP) }\end{array}$ & $\begin{array}{c}\text { vert. and horiz. } \\
\text { phase }\end{array}$ & 10 & 13 & $30 \%$ \\
\hline $\begin{array}{l}\text { Determine layer } \\
\text { temperature to 3\% }\end{array}$ & I'/I & 33 & 108 & $230 \%$ \\
\hline
\end{tabular}


Table 4: RPA/SPS measurement performance

\begin{tabular}{|l|c|c|c|c|}
\hline Measurement & Instrument & Sensitivity & Dynamic Range & Accuracy \\
\hline Neutral density & SPS & $0.4 \mu \mathrm{Pa}$ & $1.3 \mu \mathrm{Pa}-665 \mathrm{mPa}$ & $\pm 30 \%$ \\
\hline Ion density & RPA & $300 \mathrm{~cm}^{-3}$ & $300-5 \times 10^{7} \mathrm{~cm}^{-3}$ & $\pm 5 \%$ \\
\hline Ion temperature & RPA & $100 \mathrm{~K}$ & $500-3000 \mathrm{~K}$ & $\pm 50 \mathrm{~K}$ \\
\hline $\begin{array}{l}\text { Light/Heavy Ion } \\
\text { Composition }\end{array}$ & RPA & $\pm 10 \%$ & $10-100 \%$ & $\pm 10 \%$ \\
\hline
\end{tabular}




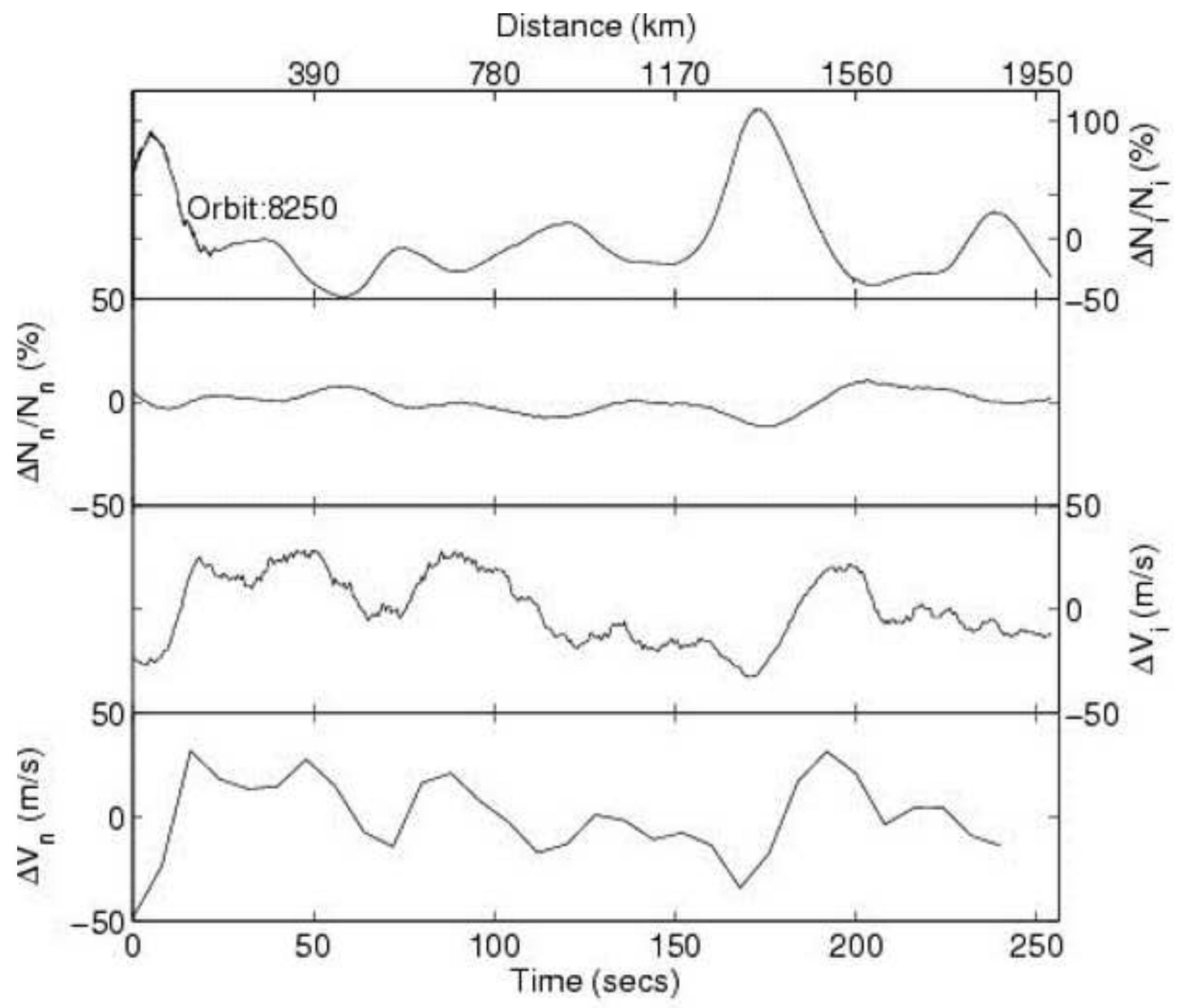




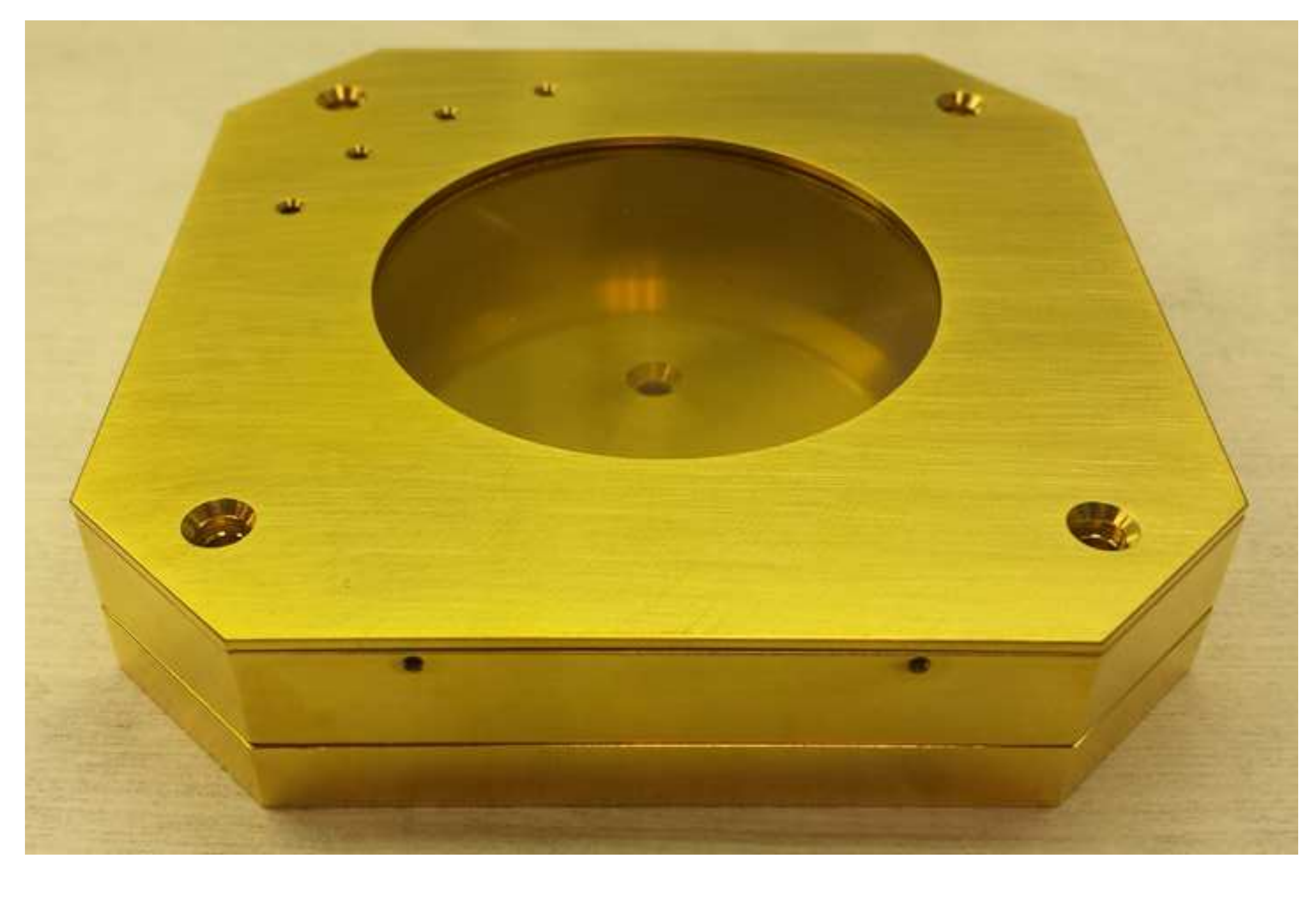

figure2

$$
2
$$

.

(
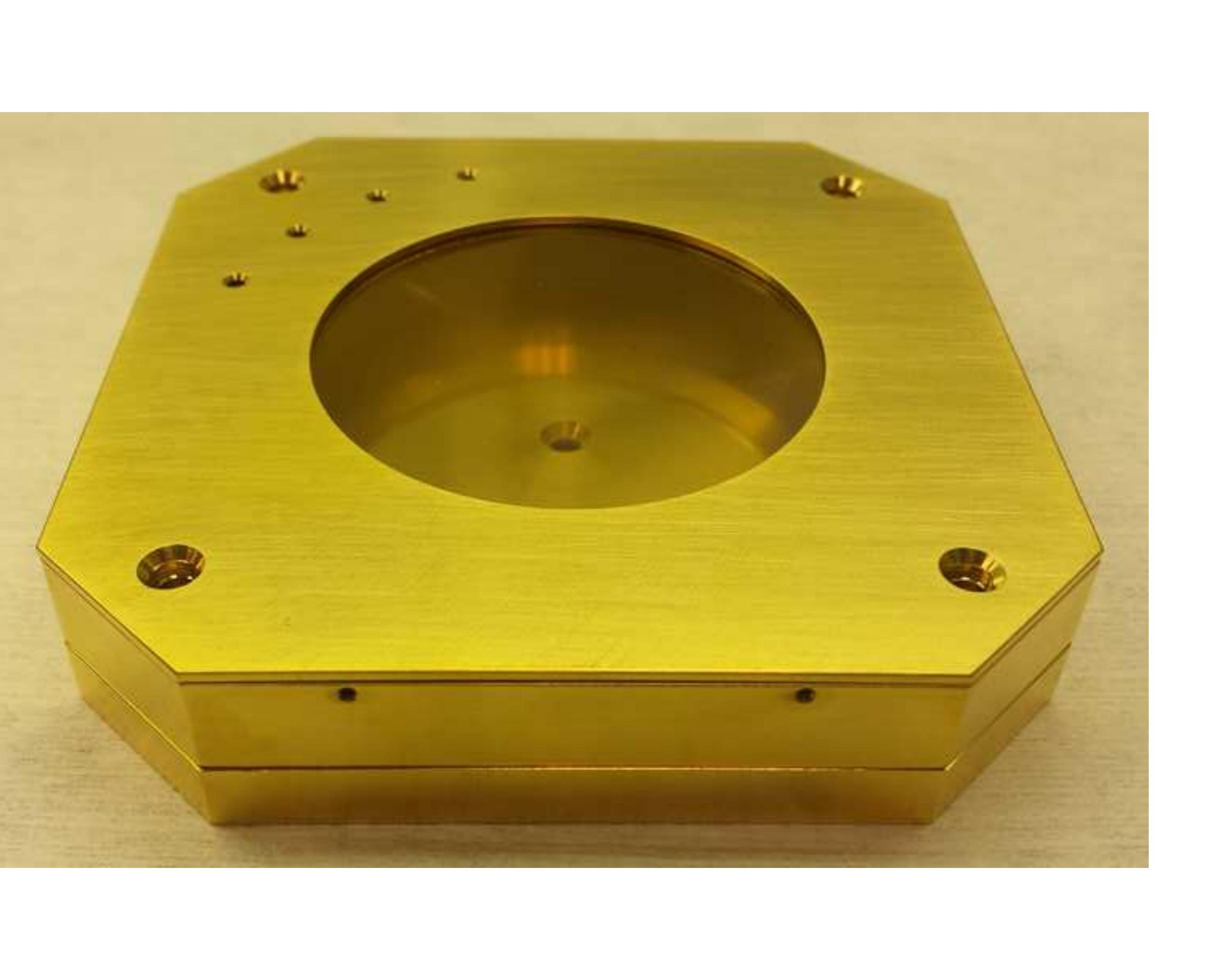


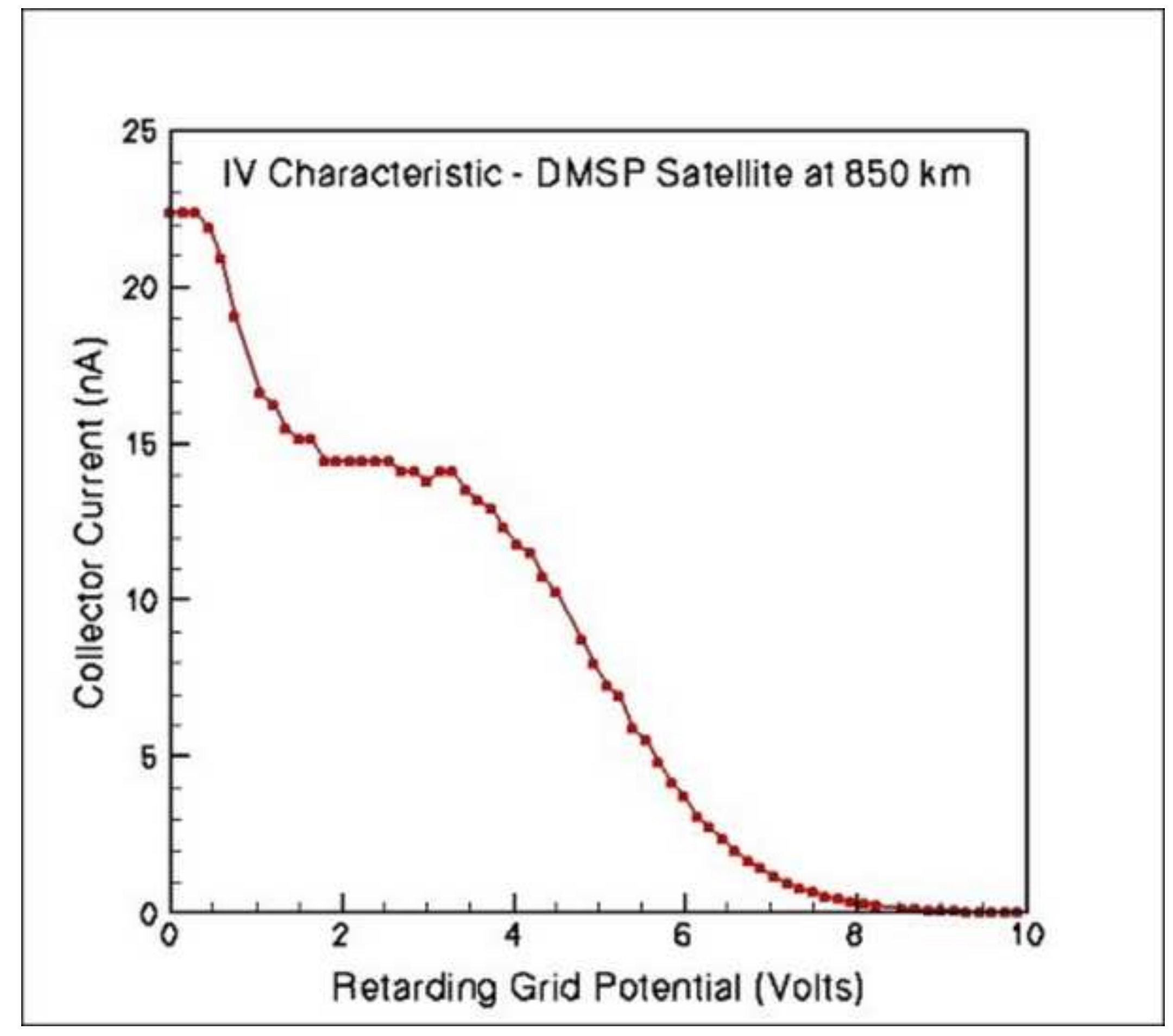



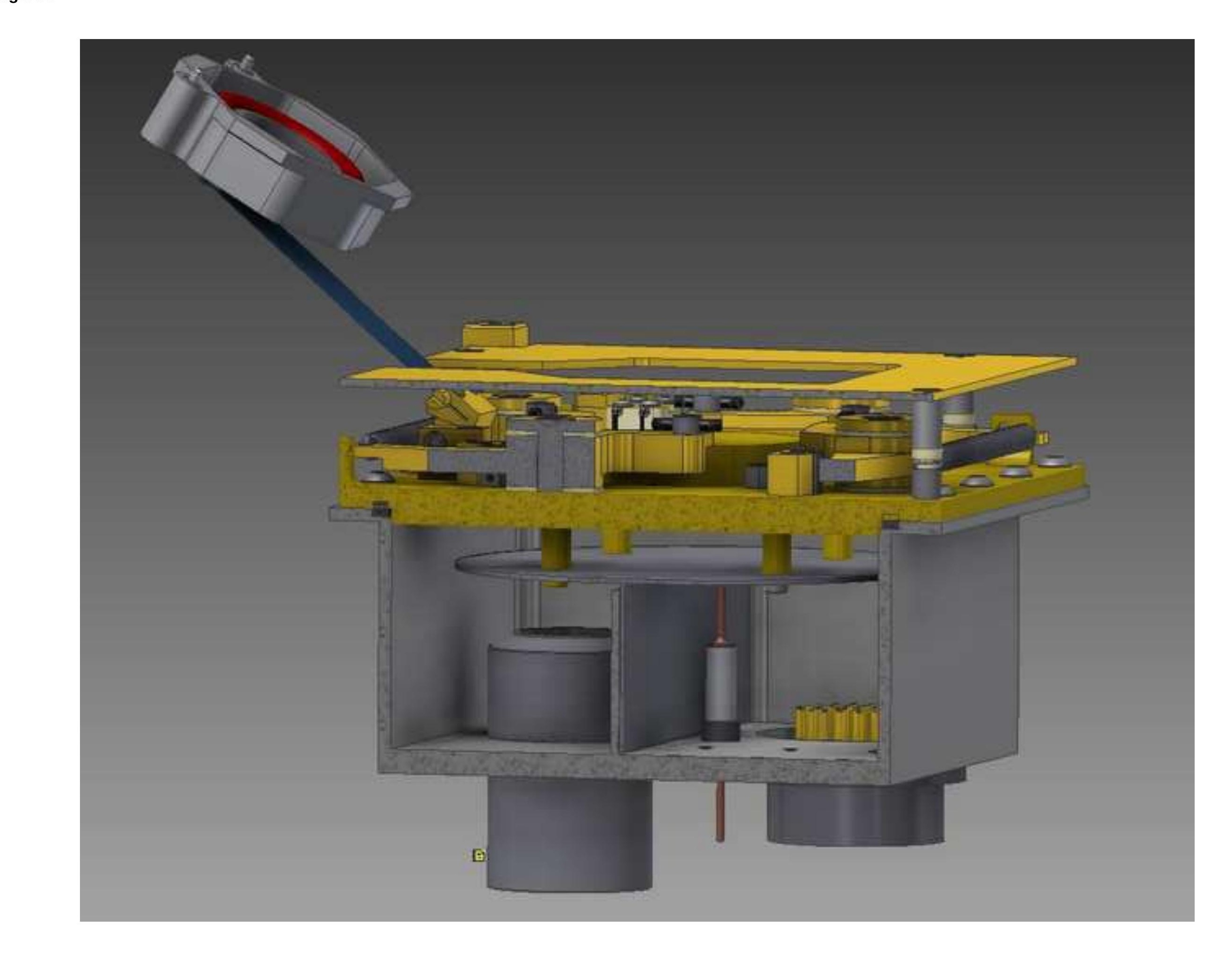

.

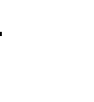

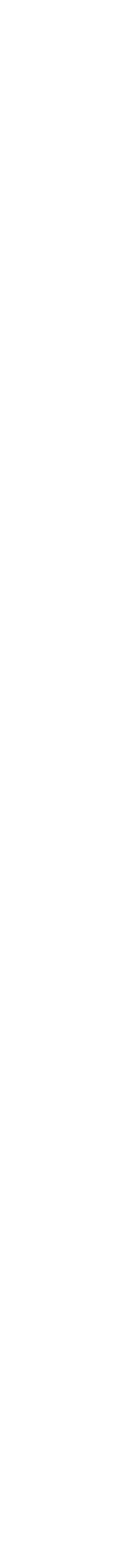
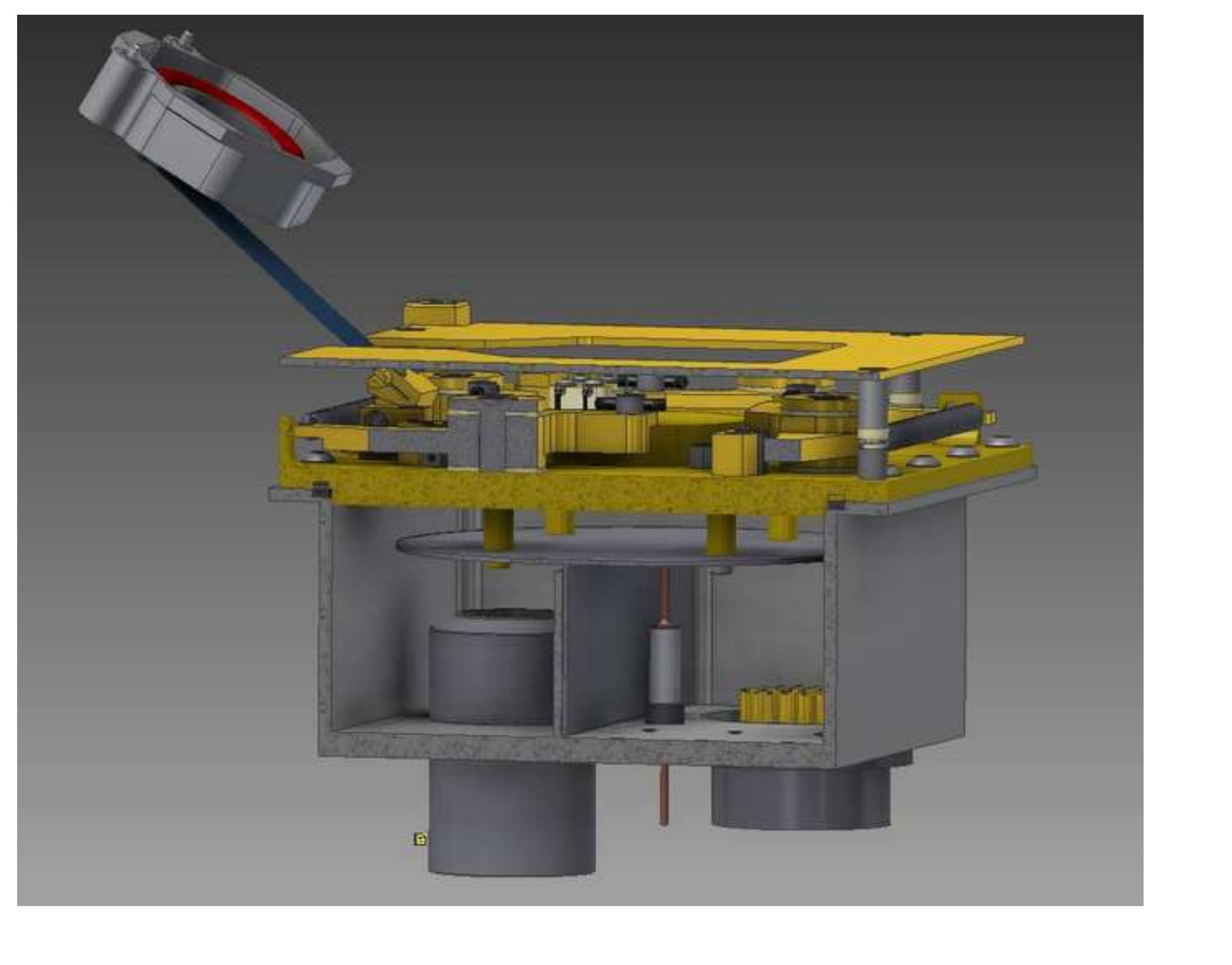

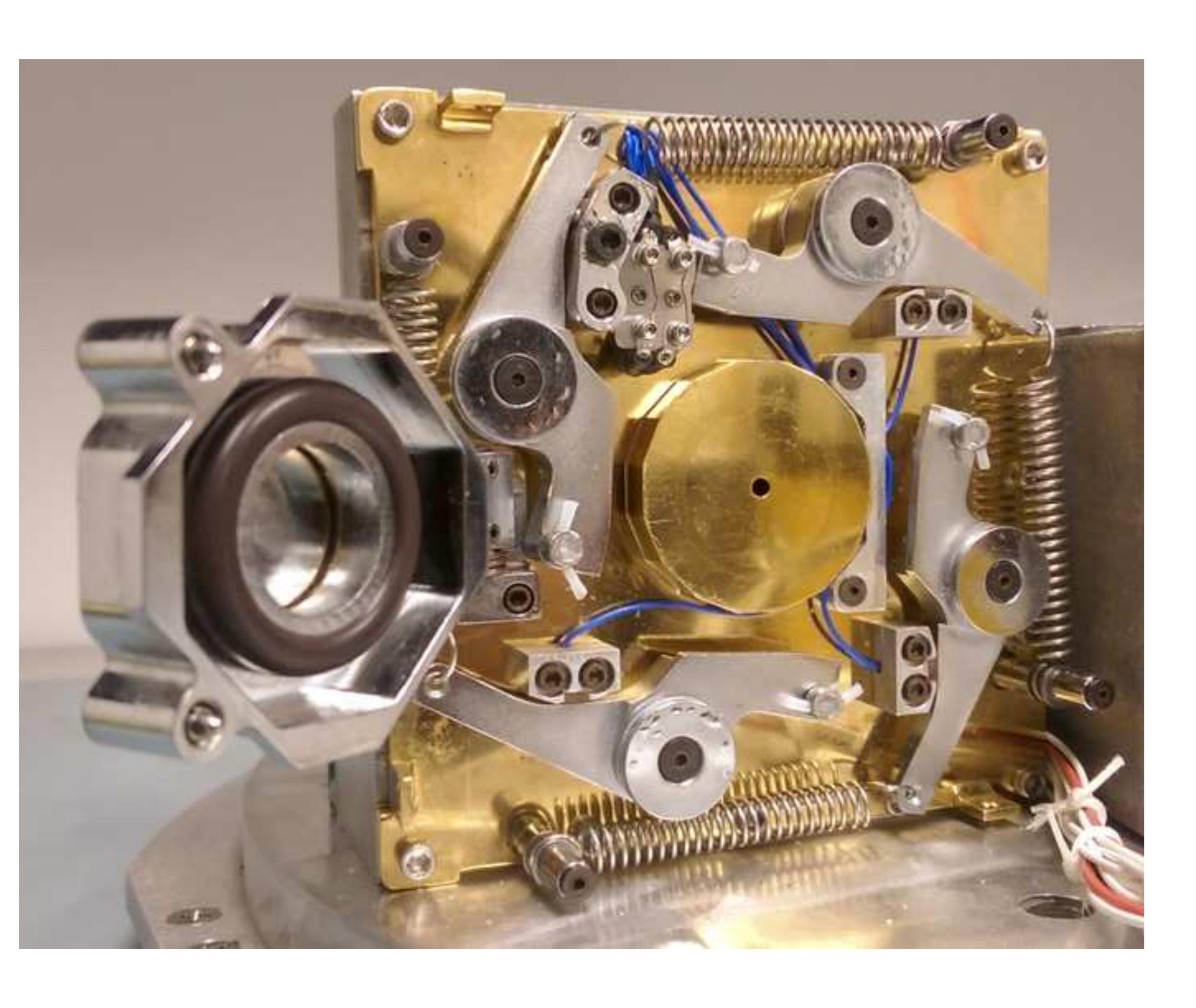

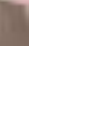
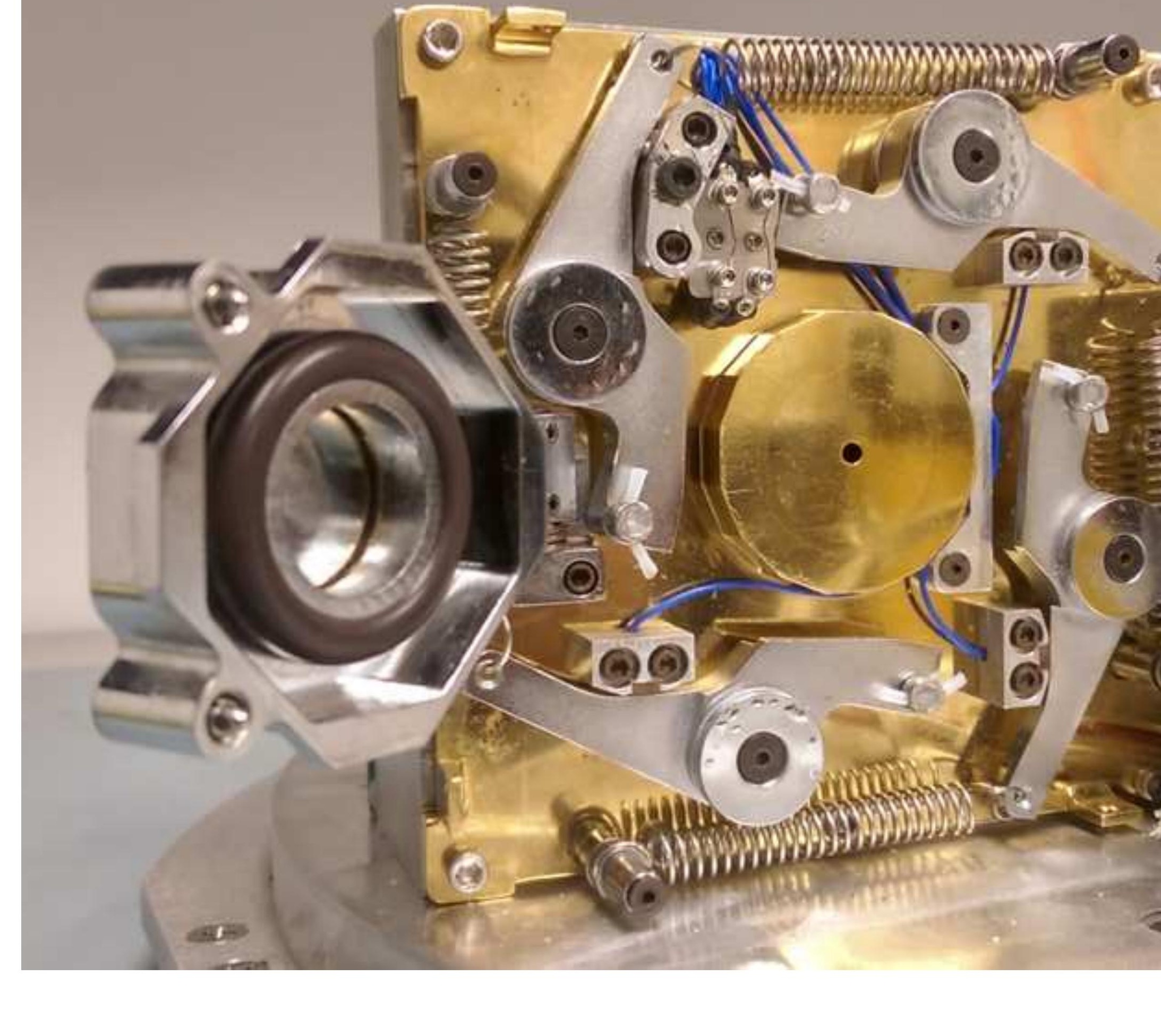

.

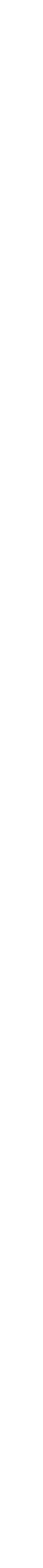




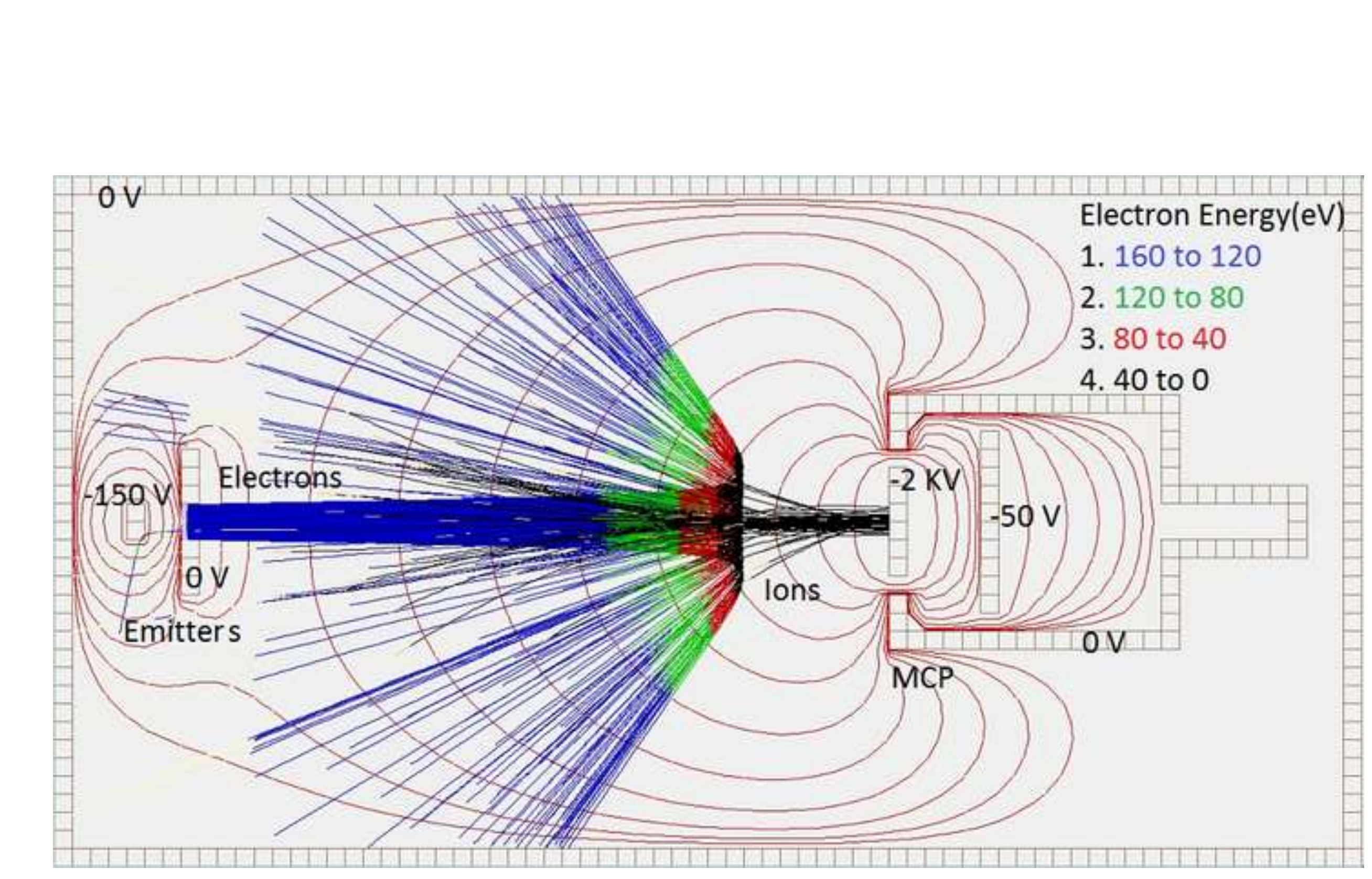

\section{.}

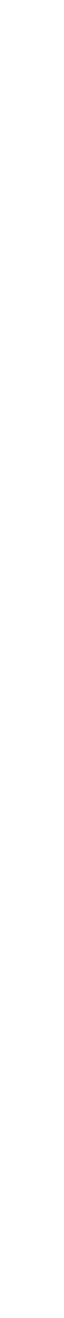

. 


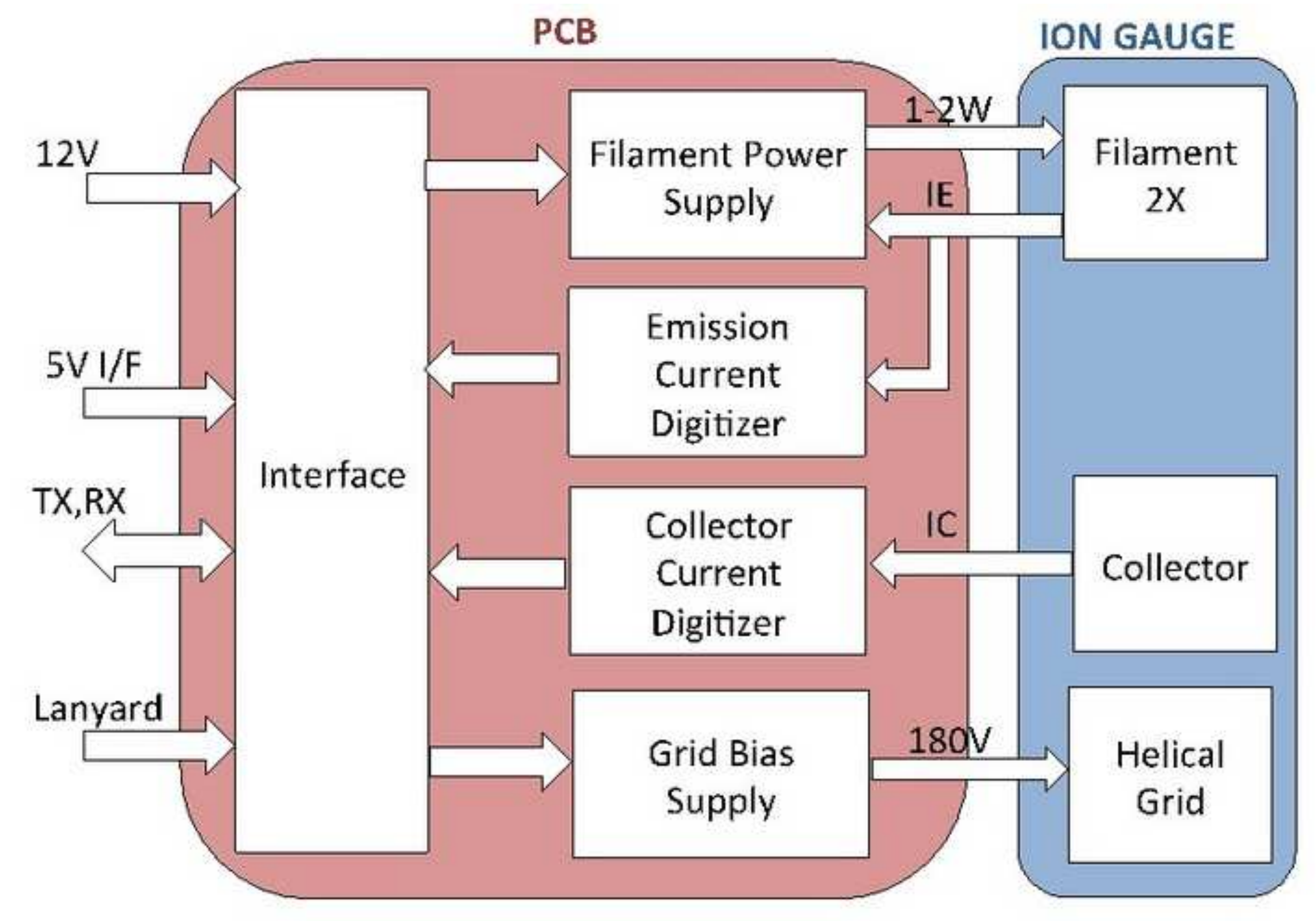




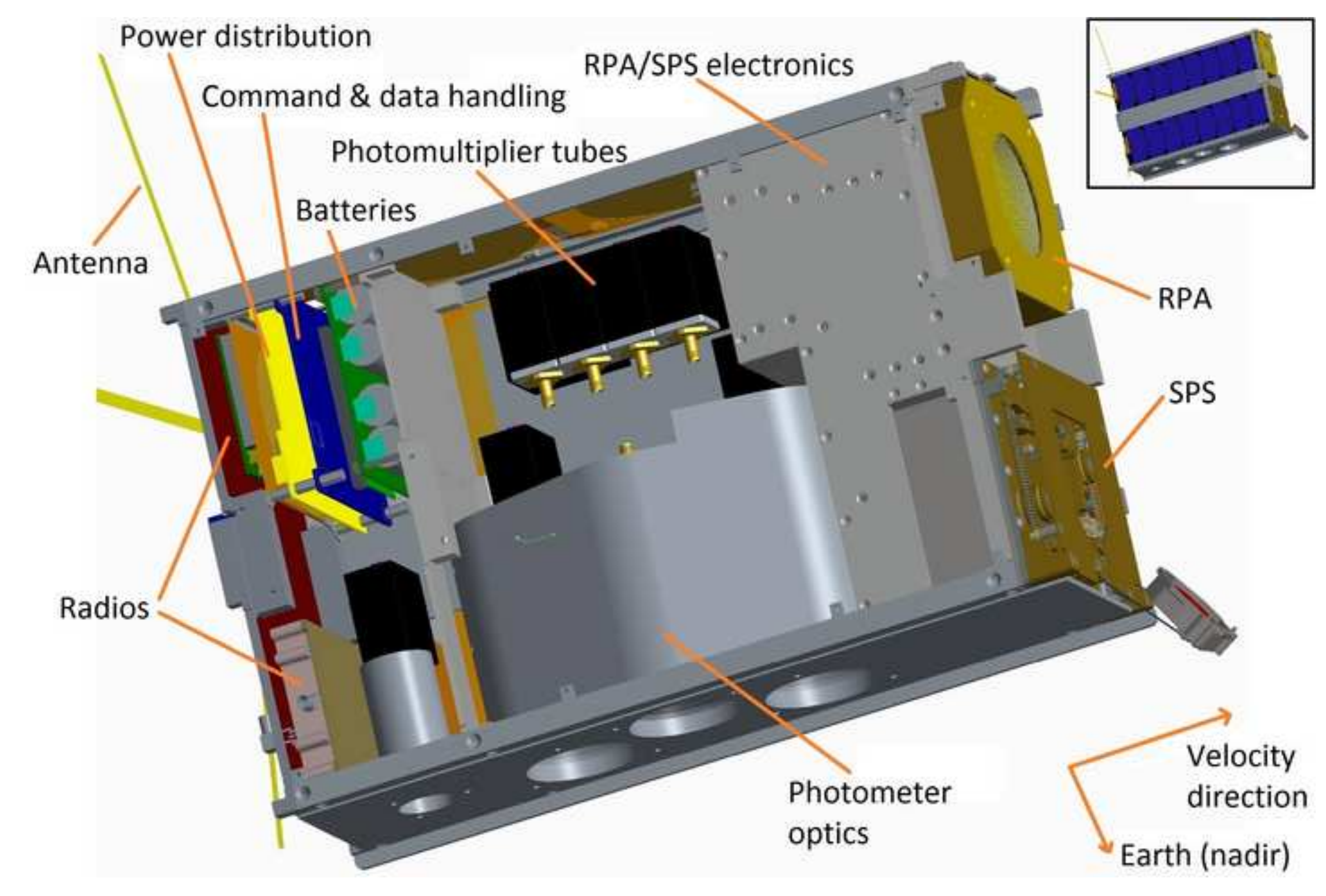


figure10

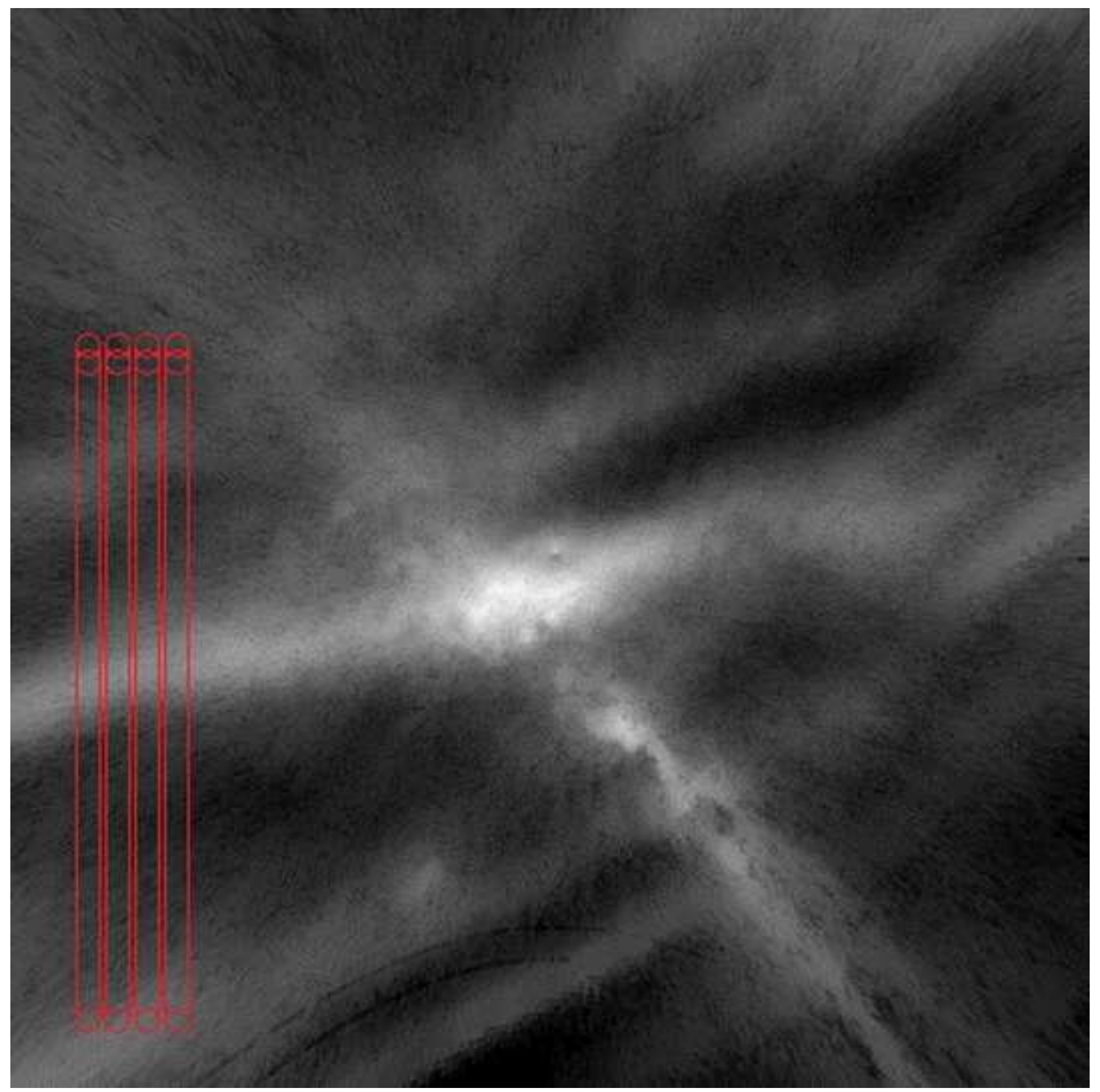




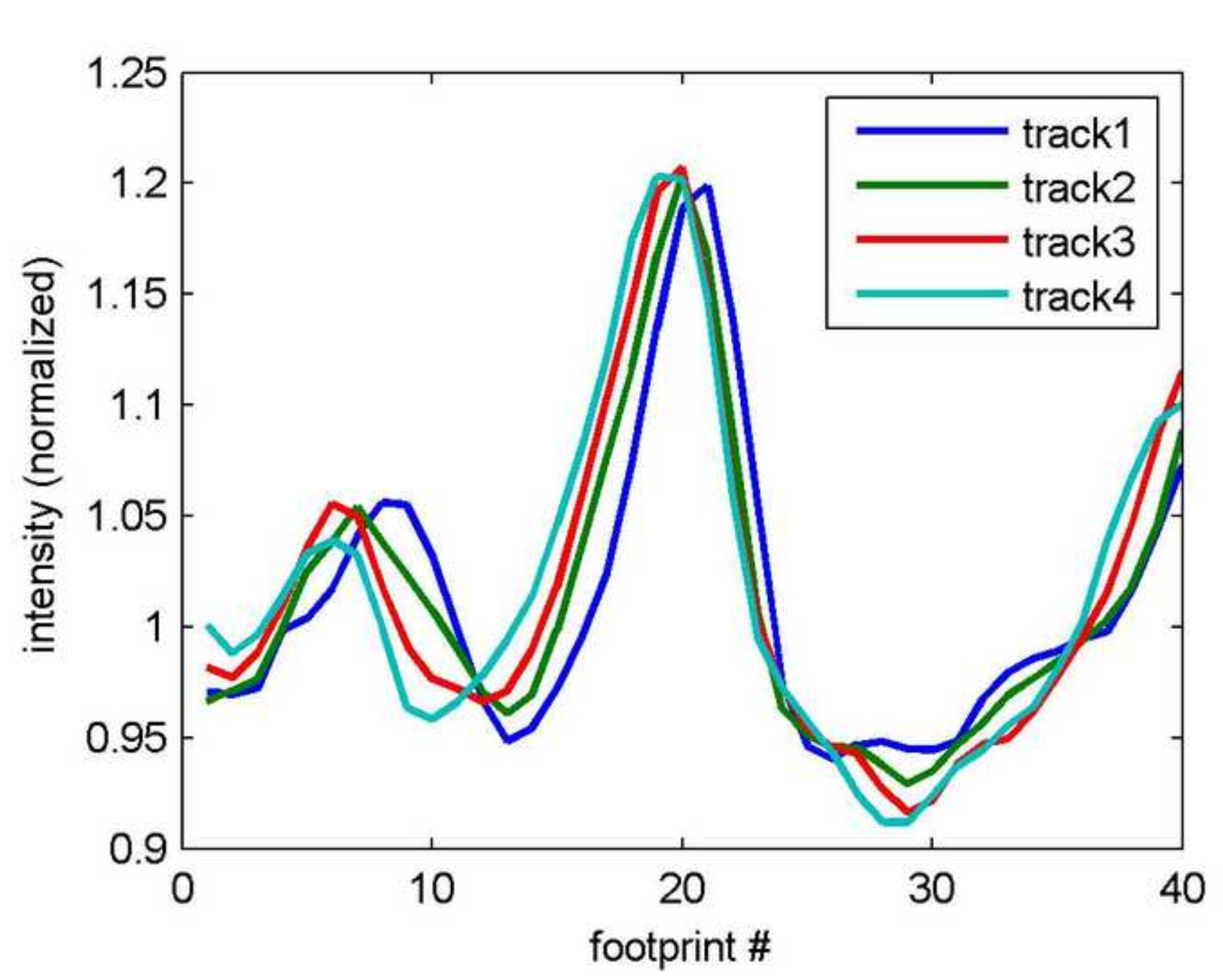

